\title{
Independent Pathways Downstream of the Wnd/DLK MAPKKK Regulate Synaptic Structure, Axonal Transport, and Injury Signaling
}

\author{
Susan Klinedinst, Xin Wang, Xin Xiong, Jill M. Haenfler, and Catherine A. Collins \\ Department of Molecular Cellular and Developmental Biology, University of Michigan, Ann Arbor, Michigan 48109-1048
}

\begin{abstract}
Mitogen-activated protein (MAP) kinase signaling cascades orchestrate diverse cellular activities with common molecular players. To achieve specific cellular outcomes in response to specific signals, scaffolding proteins play an important role. Here we investigate the role of the scaffolding protein JNK interacting protein-1 (JIP1) in neuronal signaling by a conserved axonal MAP kinase kinase kinase, known as Wallenda (Wnd) in Drosophila and dual leucine kinase (DLK) in vertebrates and Caenorhabditis elegans. Recent studies in multiple model organisms suggest that Wnd/DLK regulates both regenerative and degenerative responses to axonal injury. Here we report a new role for Wnd in regulating synaptic structure during development, which implies that Wnd is also active in uninjured neurons. This synaptic role of Wnd can be functionally separated from the role of Wnd in axonal regeneration and injury signaling by the requirement for the JIP1 scaffold and the p38b MAP kinase. JIP1 mediates the synaptic function of Wnd via p38, which is not required for injury signaling or new axonal growth after injury. Our results indicate that Wnd regulates multiple independent pathways in Drosophila motoneurons and that JIP1 scaffolds a specific downstream cascade required for the organization of presynaptic microtubules during synaptic development.
\end{abstract}

\section{Introduction}

Neurons use mitogen-activated protein kinase (MAPK) signaling cascades to regulate many different processes, including synaptic development and plasticity, axonal growth, and survival. A conserved upstream regulator of MAPK signaling, named Wallenda (Wnd) in Drosophila and dual leucine kinase (DLK) in vertebrates and Caenorhabditis elegans, has received much recent attention for its roles in regulating neuronal responses to axonal injury. This kinase becomes activated by axonal injury and mediates different downstream responses depending on the cell type and context: regenerative axonal growth, cell death, axonal degeneration, and protection from degeneration (for review, see Tedeschi and Bradke, 2013).

In contrast to these postdevelopmental roles, previous studies have suggested that Wnd/DLK is highly regulated during devel-

\footnotetext{
Received Nov. 3, 2012; revised May 19, 2013; accepted May 24, 2013.

Author contributions: S.K., X.W., X.X., and C.A.C. designed research;S.K., X.W., X.X., J.M.H., and C.A.C. performed research; S.K., X.W., and C.A.C. analyzed data; S.K., X.W., and C.A.C. wrote the paper.

This work was supported by National Science Foundation Grant IOS-0842701 and National Institutes of Health Grant NS069844. We thank Pavan Bhat, Ronny Ewanek, Mary Sprader, Jennifer Diep, Travis Washington, Nicolette Ognjanovski, Dhwani Joshi, and Dayna Menken for technical assistance and Aaron DiAntonio for logistical support in the early stages of this project. We thank Bill Saxton and Subhabrata Sanyal for Drosophila lines. Additionally, we thank the Bloomington Stock Center (Indiana University), the Vienna Drosophila RNAi Center, and the Developmental Studies Hybridoma Bank (University of lowa).

The authors declare no competing financial interests.

Correspondence should be addressed to Catherine A. Collins, Department of Molecular Cellular and Developmental Biology, University of Michigan, Ann Arbor, MI 48109-1048. E-mail: collinca@umich.edu.

X. Xiong's present address: Department of Cellular and Molecular Pharmacology, University of California, San Francisco, CA 94158-2517.

DOI:10.1523/JNEUROSCI.5160-12.2013

Copyright $\odot 2013$ the authors $\quad 0270-6474 / 13 / 3312764-15 \$ 15.00 / 0$
}

opment and that this regulation is important for neuronal migration, axon termination, apoptosis, and synaptic development (Chen and Tan, 2000; Collins et al., 2006; Hirai et al., 2006; Bloom et al., 2007; Grill et al., 2007; Ghosh et al., 2011).

How can a single kinase mediate such diverse and dichotomous functions in neurons? Wnd is a member of the mixed lineage family of kinases, which has been shown to function as upstream regulators of the stress-activated MAPKs, c-Jun $\mathrm{NH}_{2}$ terminal kinase (JNK) and p38 (Fan et al., 1996). Toward understanding the mechanism for the multiple functions of Wnd, we investigated the role of scaffolding proteins. By coordinating interactions between specific MAPKs and their activators, inactivators, or substrates, scaffolding proteins can influence when and where MAPKs become activated, as well as the downstream consequences of their activation (Morrison and Davis, 2003; Dhanasekaran et al., 2007).

We focused our study on the JNK interacting proteins (JIPs), which have been implicated in a number of JNKregulated processes in neurons (Whitmarsh, 2006; Koushika, 2008). The Drosophila genome encodes two JIP proteins: JIP1 (APLIP1) and JIP3, also known as Sunday Driver (Syd). In both vertebrate and Drosophila cells, it has been shown that JIP1 mediates the activation of JNK by Wnd/DLK (Whitmarsh et al., 1998; Nihalani et al., 2001; Whitmarsh, 2006; Horiuchi et al., 2007). Both JIP1 and JIP3/Syd are carried by kinesin motors in axons (Verhey et al., 2001) and influence the process of axonal transport (Bowman et al., 2000; Byrd et al., 2001; Taru et al., 2002; Horiuchi et al., 2005). Because functional axonal transport machinery is required for injury signaling (Abe and Cavalli, 2008; Xiong et al., 2010), we needed to con- 
sider the relationship between JIP1 and the roles of Wnd in axonal transport and signaling.

Our findings suggest that these processes can be functionally separated. Characterization of jip 1 null mutants has revealed a new role for Wnd in regulating the structure of synaptic microtubules during development of the Drosophila neuromuscular junction (NMJ). This developmental role, which requires JIP1 and the downstream p38b MAPK, is distinct from the roles of Wnd in axonal transport and injury signaling, which do not require p38. Hence, the JIP1 scaffold promotes a specific synaptic function for Wnd and MAPK signaling.

\section{Materials and Methods}

Generation of jip1 mutant. The jip $1^{e x}$ allele was created by the imprecise excision of the P-element insertion P-Aplip1 ${ }^{D G 20707}$, which lies in the $3^{\prime}$ UTR of JIP1/Aplip1. Approximately 260 independent lines were screened by PCR to uncover one deletion that removed the entire JIP1/Aplip1 locus.

Genetics. The following strains were used in this study: Canton S [wildtype (WT)], puc-lacZ ${ }^{\mathrm{E} 69}$ (Martín-Blanco et al., 1998), BG380-Gal4 (Budnik et al., 1996), m12-Gal4 [P(Gal4) $\left.{ }^{5053 \mathrm{~A}}\right]$ (Ritzenthaler et al., 2000), RRa(eve)-Gal4 (Fujioka et al., 2003), OK6-Gal4 (Aberle et al., 2002), wnd ${ }^{1}, w n d^{2}, w n d^{3}$ (Collins et al., 2006), hiw ${ }^{N D 8}$ (Wan et al., 2000), $h_{i w}{ }^{\Delta N}$ (Wu et al., 2005), UAS-Fos ${ }^{D N}$ (Eresh et al., 1997), UASBsk(Jnk) ${ }^{\mathrm{DN}}$ (Weber et al., 2000), $\Delta p 38 a$ (Craig et al., 2004), $p 38 b^{\Delta 45}$, $p 38 b^{\Delta 25} ; \Delta p 38 a$ (Vrailas-Mortimer et al., 2011), UAS-p38b ${ }^{\text {DN }}$ (AdachiYamada et al., 1999), syd $d^{Z 4}, s y d^{2 H}$ (Bowman et al., 2000), and jip $1^{\text {ek4 }}$, UAS-JIP1 $\Delta$ KBD, genomic JIP1 (Horiuchi et al., 2005). Df(3L)ED229 (wnd), Df(3L)Fpa2 ( jip1), Df(2L)b80e3 ( p38b), UAS-bsk-RNAi (TRiPJF01275), UAS-p38b-RNAi (TRiP-JF03341), UAS-wnd-RNAi (TRiPJF02675), p38b ${ }^{\text {KG01337, }}$ P-Aplip1 ${ }^{\text {DG20707, }}$, and Futsch ${ }^{\mathrm{EP}(\mathrm{x}) 1419}$ were obtained from the Bloomington Stock Center. UAS-wnd-RNAi (26910) was acquired from the Vienna RNAi Center (Dietzl et al., 2007). UAS$D c r 2$ was a gift from Stefan Thor (Linkoping University, Linkoping, Sweden). GeneSwitch elav-Gal4 driver (GSelav) was used to control temporal expression of UAS transgenes in neurons (Osterwalder et al., 2001). To activate the GSelav driver, flies were reared on standard food that contained $20 \mu \mathrm{g} / \mathrm{ml} \mathrm{RU}-486$ (11 $\beta$-[ $p$-(dimethylamino)phenyl]$17 \beta$-hydroxy-17-(1-propynyl)estra-4,9-dien-3-one), a nonlethal dose of the drug. Male larvae were used for all experiments using the BG380Gal4 driver. For other experiments, larvae of both sexes were used.

Immunocytochemistry. Larvae were dissected in PBS and fixed in either 4\% paraformaldehyde in PBS or Bouin's fixative for 15-30 min, depending on the antibodies used. Antibodies were used at the following dilutions in PBS with $0.3 \%$ Triton X-100 and 5\% normal goat serum: mouse anti-Futsch, 1:100 (22c10; Developmental Studies Hybridoma Bank); rabbit anti-Drosophila vesicular glutamate transporter (DVGLUT) (Daniels et al., 2004), 1:5000; rat anti-elav (7E8A10; Developmental Studies Hybridoma Bank), 1:50; mouse anti-acetylated tubulin (SigmaAldrich), 1:100; Cy3 goat anti-HRP (Jackson ImmunoResearch), 1:500; Cy5 goat anti-HRP (Jackson ImmunoResearch), 1:100; and Alexa Fluor 488 rabbit anti-GFP (Invitrogen), 1:1000. For secondary antibodies, Cy3 and Alexa Fluor 488-conjugated goat anti-rabbit, anti-mouse, and antirat (Invitrogen) were used at 1:1000.

Imaging and quantification. Confocal images were collected at room temperature on an Improvision spinning-disk confocal system (PerkinElmer Life and Analytical Sciences). All imaging and quantification were conducted with Volocity software (PerkinElmer Life and Analytical Sciences). Similar settings were used to collect all compared genotypes and conditions.

To quantify the mean intensity of $p u c-$ lacZ expression, we used the protocol described previously (Xiong et al., 2010).

Futsch bundling was quantified as described previously (Viquez et al., 2006). Briefly, larvae were stained with Futsch and DVGLUT antibodies to label both the cytoskeleton and the synaptic boutons, respectively. Futsch staining that colocalized with DVGLUT was classified as either unbundled (looped, splayed, punctate, or missing) or bundled Futsch (tightly wound filamentous Futsch staining). The synaptic area of un- bundled and bundled Futsch were measured, and the area of unbundled Futsch was divided by the total Futsch area.

The axonal transport severity index was ranked by qualitative assessment of the number and size of axonal accumulations for the synaptic vesicle marker DVGLUT, while blind to genotype. Individual nerves were given a score of 0 to 4 depending on severity, with 4 being the greatest amount of axonal accumulations.

The regeneration ratio was quantified as the fraction of injured axons that exhibited sprouting (at least five branches) per genotype, while blind to the genotype, as described by Xiong et al. (2010).

Nerve crush assay. The segmental nerves of third-instar larvae were subjected to nerve crush injury as described previously (Xiong et al., 2010).

\section{Results}

\section{Comparison of JIP1 and JIP3 in axonal transport and injury signaling}

To study the role of JIP1/APLIP1 in Wnd signaling, we generated a null allele via imprecise excision of the P-Aplip $1^{D G 20707}$ transposon. jip $1^{e x}$ removes the entire jipl coding region, leaving the flanking genes $L y s X$ and $m w h$ intact (Fig. $1 A$ ). Unlike the larval lethality observed for mutations in the JIP3 homolog Syd (Bowman et al., 2000), jip $1^{e x} / j i p 1^{e x}$ and $j i p 1^{e x} / D f$ mutants develop into fully viable adults. Defects in axonal transport, as measured by accumulations of the synaptic vesicle marker DVGLUT in segmental nerves, were also less severe for $j i p 1^{e x}$ mutants compared with jip3 mutants (Fig. 1B,C). The axonal transport defect of jip $1^{\text {ex }}$ can be rescued by the presence of a transgene containing one copy of genomic jip1 (Fig. 1C).

Wnd regulates a transcriptional response to axonal injury, which can be measured by the induction of the puc-lacZ reporter (Martín-Blanco et al., 1998) in response to a larval segmental nerve crush (Xiong et al., 2010). Injury signaling in jip $1^{\text {ex }}$ mutant animals is slightly reduced at $8 \mathrm{~h}$ but reaches levels similar to WT animals within $24 \mathrm{~h}$ after injury (Fig. 1D). In contrast, injury signaling was dramatically inhibited in the jip 3 mutant animals at both 8 and $24 \mathrm{~h}$ after injury (Fig. $1 D$ ). These results suggest that JIP3/Syd plays an essential role in the injury signaling mechanism, whereas JIP1 is dispensable. It has been shown previously that general inhibition of axonal transport can diminish the induction of puc-lacZ (Xiong et al., 2010); therefore, the divergent phenotypes for jip 1 and jip 3 in injury signaling may be an indirect consequence of their different effects on axonal transport (Fig. $1 B, C)$. Because axonal transport plays a fundamental role in neurons and its disruption would affect many cellular pathways, this was an important concern in understanding the function of JIP1. Therefore, we asked whether JIP1 played other roles in neurons that could be functionally or phenotypically separated from its role in axonal transport.

\section{JIP1 promotes the development of presynaptic boutons}

The most striking phenotype observed for $j i p 1^{e x}$ mutants was the enlargement of the synaptic boutons at the larval NMJ (Fig. 2A,B). The most proximal boutons were particularly enlarged, showing an approximately twofold increase in diameter compared with WT synapses (Fig. 2B). We also measured a greater than twofold increase in the total number of boutons that exceeded $5 \mu \mathrm{m} / \mathrm{NMJ}$ : WT animals had an average of one bouton per NMJ that reached this size, but jip1 mutants had an average of three boutons per NMJ that were $>5 \mu \mathrm{m}$ (SEM of $0.54, p=0.03$ ) (data not shown). In contrast to the enlarged bouton sizes, we observed no differences in the overall number of boutons or branches (see Fig. 6B).

Surprisingly, jip $1^{e k 4}$ mutants, which carry a point mutation within the kinesin binding domain (Horiuchi et al., 2005) and 
A

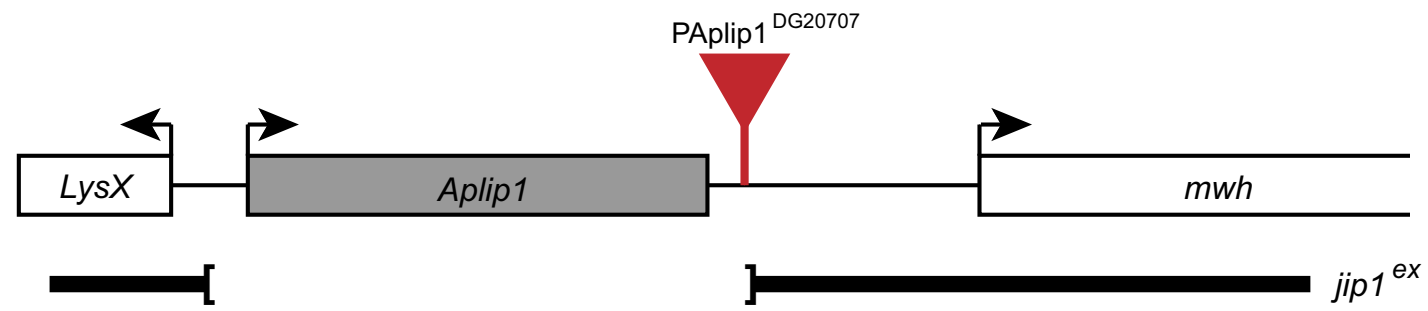

B
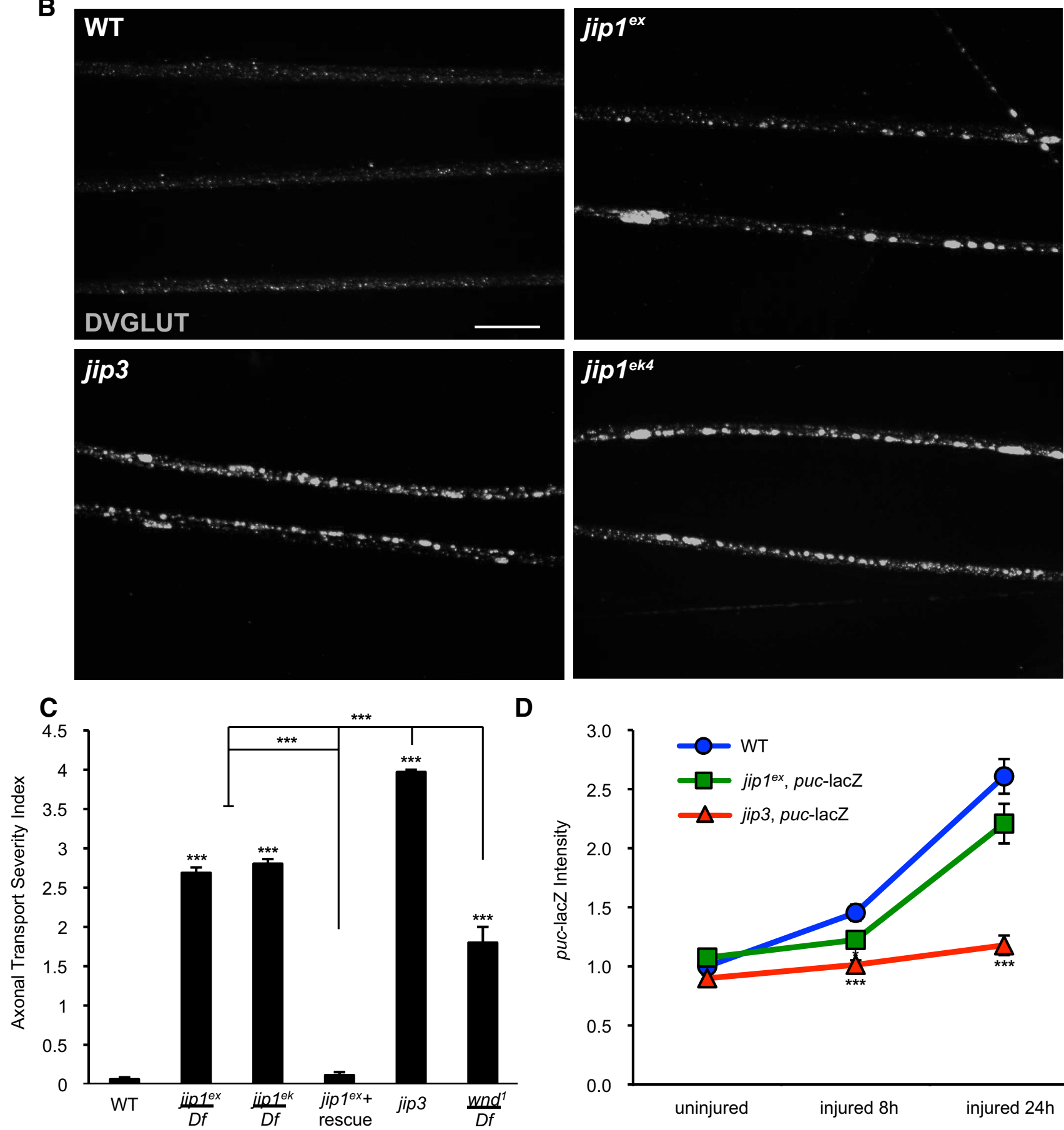

D

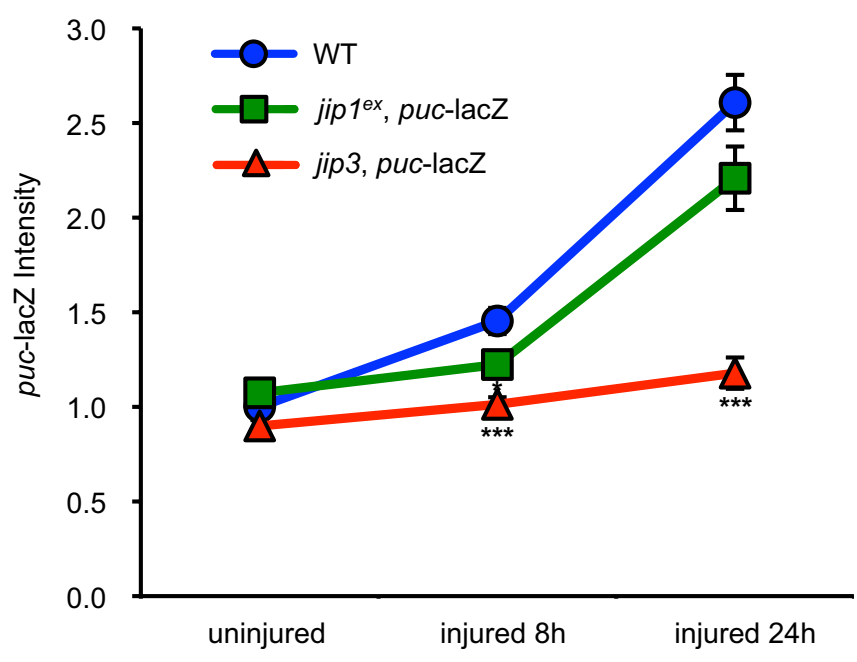

Figure 1. Comparison of JP1 and JIP3 in injury signaling and axonal transport. A, Schematic of the JIP1/APLIP1 genomic region depicting the jip $7^{e x}$ excision deletion mutation. The jip1/Aplip1 locus with flanking genes $L y s X$ and $m w h$. The jip ${ }^{\text {TXX }}$ null allele was created by imprecise excision of $P$-Aplip ${ }^{\text {DG20707 }}$. B, Segmental nerves from third-instar larvae immunostained with DVGLUT. Small punctae of DVGLUT are observed in WT nerves. jip $7^{\text {ex }}$ null mutation caused accumulations of DVGLUT in nerves consistent with defective axonal transport. A similar amount of accumulations were observed in the jip $7^{\text {ek4 }}$ hypomorphic allele. jip3 mutants $\left(\right.$ syd $\left.d^{24} / s y d^{2 H}\right)$ displayed an increase in the number of DVGLUT accumulations compared with jip 1 mutants. C, Quantification of the axonal transport severity index. The severity of the DVGLUT accumulation phenotype was ranked by qualitative assessment of the number and size of axonal accumulations (see Materials and Methods). Note that defects in jip 1 and jip3 mutants are stronger than the strongest observed phenotype in wnd mutants. D, Quantification of puc-lacZ. The mean intensity (Figure legend continues.) 
displayed comparable defects in axonal transport as jip $1^{e x}$ (Fig. $1 B, C$ ), did not affect bouton morphology (Fig. 2B). This observation suggested that the role of JIP1 in controlling synaptic morphology may be separable from its role in axonal transport. Similarly, neuronal expression of a JIP1 transgene lacking the kinesin binding domain (UAS-JIP1 $\triangle \mathrm{KBD}$ ) also had no effect on bouton morphology (Fig. $2 B, C$ ), although these animals display strong defects in axonal transport (Horiuchi et al., 2005). In jip3 mutants, which exhibit the strongest defect in axonal transport, the bouton diameter was actually slightly decreased compared with control synapses (Fig. $2 A, B$ ). Because the synaptic phenotypes did not correlate with the axonal transport phenotypes, they suggest an independent function for JIP1 in the regulation of synaptic structure.

To verify that the enlarged bouton phenotype was specific for JIP1, we used the UAS/Gal4 system to drive expression of a UASJIP1 transgene using the neuronal BG380-Gal4 driver in a jip $1^{\text {ex }}$ mutant background. This rescued the enlarged bouton phenotype (Fig. $2 A, C$ ). Expression of the JIP1 transgene alone in a WT background also resulted in a slight but significant increase in the maximum bouton diameter (Fig. 2C). The similarity between gain-of-function and loss-of-function phenotypes for jip1 was observed previously for defects in axonal transport (Horiuchi et al., 2005), and, given the hypothesized role of JIP1 as a scaffolding protein (Whitmarsh and Davis, 1998; Whitmarsh et al., 1998), these results are not unexpected.

To determine whether the enlarged boutons in jip1 mutant animals resulted from a failure to maintain synaptic structure or whether JIP1 played a role in synaptic development, we examined the synaptic morphology of jip1 mutant synapses in younger animals. We found that second-instar animals, similar to thirdinstar animals, had an average of 2.5 enlarged boutons ( $\geq 5 \mu \mathrm{m})$ per NMJ, but these enlarged boutons were slightly smaller in diameter (Fig. 2D and data not shown) than in third-instar larvae (Fig. 2B). We interpret that the abnormal boutons form early in NMJ development and become larger with time. These observations implicate a role for JIP1 in regulating the development of synaptic boutons at the NMJ.

\section{JIP1 is required for microtubule organization in synaptic boutons}

It is well established that synaptic morphology depends on cytoskeletal organization (Jin and Garner, 2008; Goellner and Aberle, 2012) and that vertebrate JIP1 participates in controlling microtubule dynamics in neurons (Chang et al., 2003; Tararuk et al., 2006). Therefore, we wanted to determine whether the increased bouton size reflected changes in the synaptic microtubules. A particularly useful marker for synaptic microtubules is the neuronal-specific microtubule binding protein Futsch (homologous to MAP1B), which plays a critical role in microtubule organization at the Drosophila NMJ (Hummel et al., 2000; Roos et al., 2000). Another indicator of microtubule stability is the presence of posttranslational modifications such as acetylated tubulin (Conde and Cáceres, 2009; Janke and Kneussel, 2010). At the larval NMJ, both Futsch and acetylated tubulin form a tightly

\section{$\leftarrow$}

(Figure legend continued.) of puc-lacZ is measured as described in Materials and Methods for the dorsal midline neurons. At $8 \mathrm{~h}$ after injury, puc-lacZ intensity is increased in WT animals. puc-lacZ intensity for jip1 ( jip $\left.7^{\text {ex }} / j i p 1 D f\right)$ and $j i p 3\left(s y d^{24} / s y d^{2 H}\right.$ ) mutants is significantly decreased compared with control animals. By $24 \mathrm{~h}$ after injury jip $7^{e x}$, puc-lacZ intensity increases to near WT levels, but puc-lacZ intensity in jip3 mutants is comparable with uninjured control animals. Error bars indicate mean \pm SEM. ${ }^{*} p \leq 0.01 ;{ }^{* * *} p \leq 0.0001$. Scale bars, $10 \mu \mathrm{m}$. bundled cable that runs through most of the NMJ (Ruiz-Cañada and Budnik, 2006; Fig. $3 A, B$ ). In jip1 mutants, this cable is disorganized (for Futsch) and broken (for acetylated tubulin), particularly in the largest boutons. Futsch staining becomes splayed and unbundled, whereas acetylated tubulin accumulated in a punctate, fragmented pattern, suggesting a breakdown or misregulation of the microtubule cytoskeleton (Fig. $3 A, B$ ). This disruption of the microtubule cytoskeleton is not observed in either jip $1^{e k 4}$ mutants or animals neuronally expressing the JIP1 transgene lacking the kinesin binding domain (UAS-JIP1 $\Delta \mathrm{KBD}$ ); hence, is not simply a consequence of defects in axonal transport (Fig. 3C). Importantly, both the unbundling of Futsch and the fragmentation of acetylated tubulin are rescued by the presence of a transgene containing one copy of genomic jip1 (Fig. 3A-C).

Mutations in futsch give rise to enlarged boutons (Roos et al., 2000); hence, the enlarged boutons in jip1 mutants may be the result of misregulated microtubules. We tested whether the enlarged bouton phenotype in jip1 mutants could be suppressed by increasing the expression of Futsch. Although overexpression of Futsch (using the BG380-Gal4 driver) did not significantly alter NMJ morphology in the WT background, it led to a full rescue of the enlarged bouton phenotype in jip1 mutants (Fig. 4A,B). These observations suggest that the bouton morphology defect in jip 1 mutants reflects a role for JIP1 in the organization of synaptic microtubules.

In contrast to the synaptic phenotype, overexpression of Futsch failed to rescue the axonal transport defect of jip 1 mutants (Fig. 4C,D). These observations further suggest that JIP1 plays at least two independent roles in motoneurons: (1) one in the regulation of synaptic structure and (2) another in axonal transport.

\section{The Wnd MAP kinase kinase kinase regulates synaptic morphology}

To understand the mechanism for the synaptic function of JIP1, we considered the possible role of the Wnd MAP kinase kinase kinase (MAPKKK) in regulating synaptic morphology. Studies in vertebrate and Drosophila cells suggest that JIP1 functions as a scaffolding protein for Wnd/DLK signaling (Whitmarsh et al., 1998; Nihalani et al., 2001; Horiuchi et al., 2005; Whitmarsh, 2006) and that Wnd/DLK signaling can influence microtubule structure (Eto et al., 2010; Bounoutas et al., 2011; Hirai et al., 2011; Ghosh-Roy et al., 2012). Previous characterization of wnd mutants found no obvious defects in synaptic morphology (Collins et al., 2006), but closer examination of $w n d$ mutant genotypes $\left(w n d^{1} / w n d^{2}\right.$, $w n d^{l} / D f$, and $w n d^{3} / D f$; Fig. $\left.5 A, B\right)$, as well as neuronal-specific RNAi knockdown (Fig. $5 D, E$ ), revealed an enlarged bouton phenotype similar to jipl mutants. This enlarged bouton phenotype for $w n d$, which is not as strong as the jipl phenotype, may not have been noticed in a previous study (Collins et al., 2006) because of differences in the measurement method (see Materials and Methods). The larger boutons in wnd mutants also displayed Futsch unbundling (Fig. 5A) similar to jip1 mutants. These observations suggest that JIP1 and Wnd may function together and suggest a new role for Wnd in regulating microtubule structure at synapses.

\section{The p38b MAPK regulates synaptic morphology}

Previously characterized roles for Wnd, which include the promotion of synaptic overgrowth and injury signaling (Collins et al., 2006; Xiong et al., 2010), involve downstream activation of the JNK MAPK and transcription factor Fos. We tested whether the role of Wnd in regulating the synaptic cytoskeleton could also involve signaling through these same downstream components. 

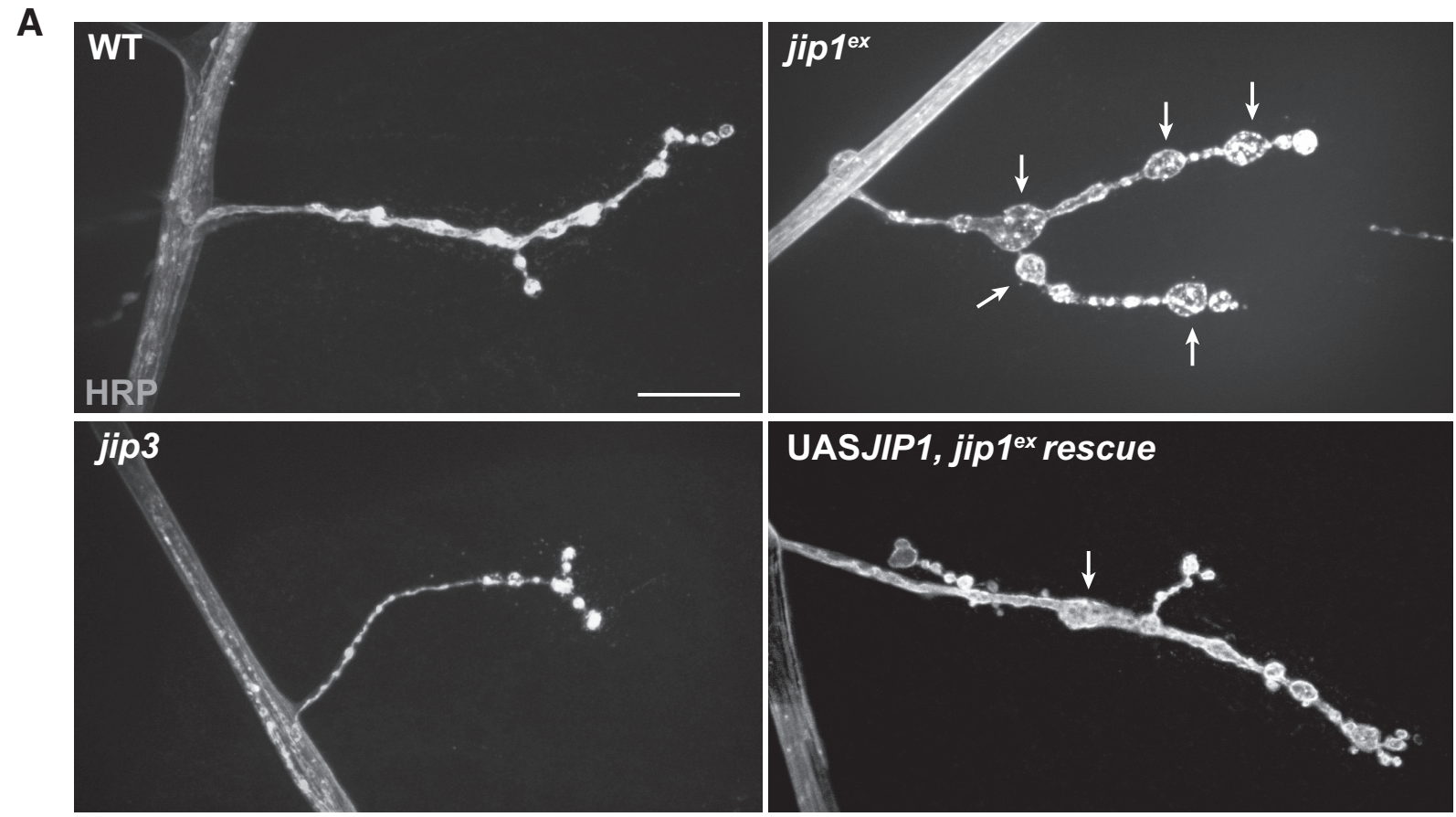

B

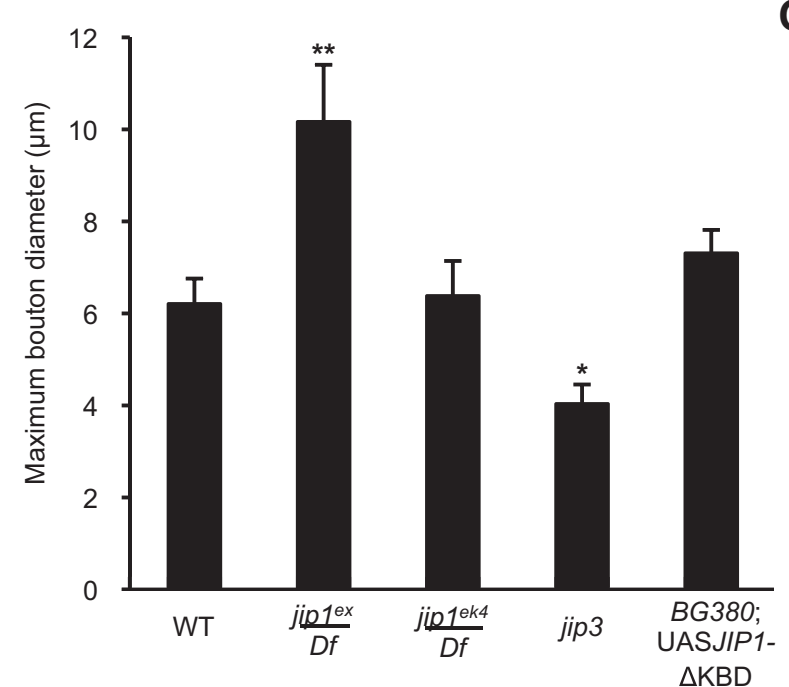

C

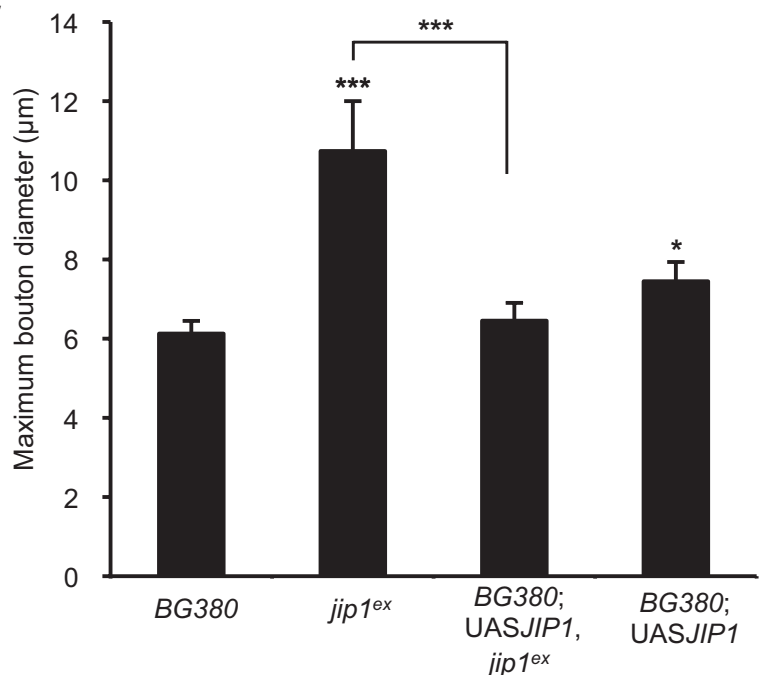

D

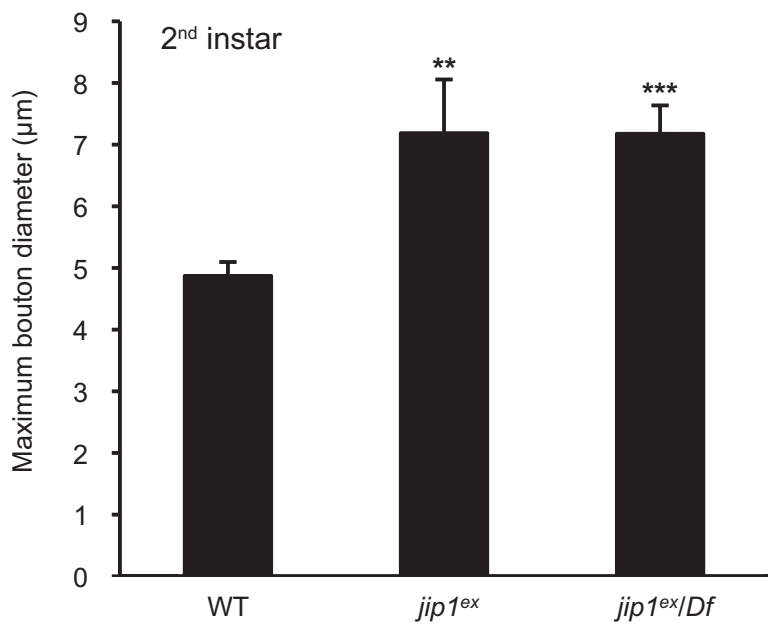

Figure 2. jip1 mutants have a synaptic NMJ phenotype. $A$, The axonal membrane at muscle 4 NMJ synapses is labeled by immunostaining with anti-HRP antibodies for WT, jip1 mutants

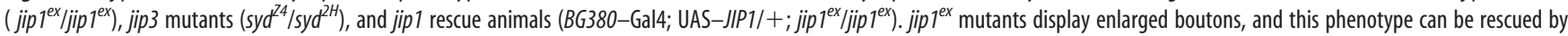
neuronal expression of a JIP1 transgene. Arrows indicate the enlarged boutons $\geq 5 \mu \mathrm{m}$. B, C, Quantification of maximum bouton diameter. $\boldsymbol{B}$,jip $7^{\text {ex }}$ mutants have larger (Figure legend continues.) 


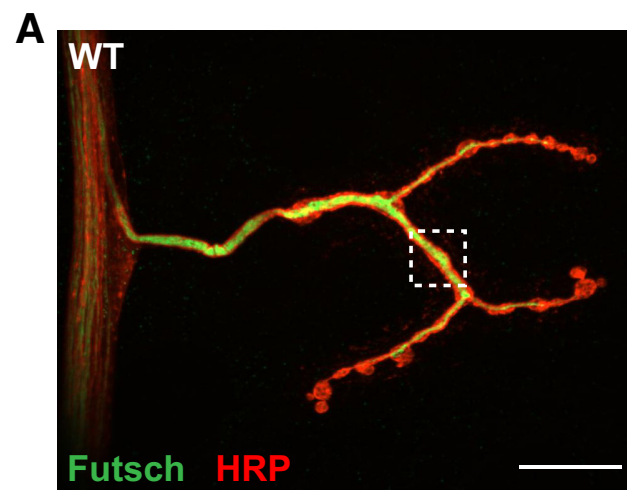

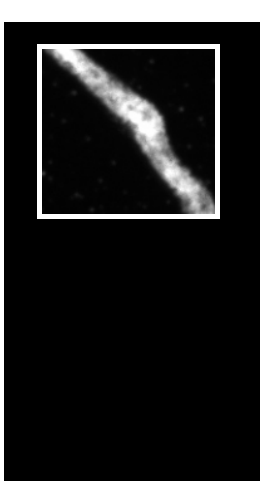

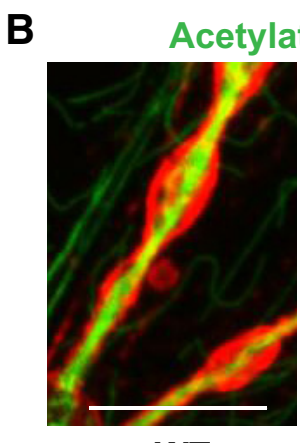

WT
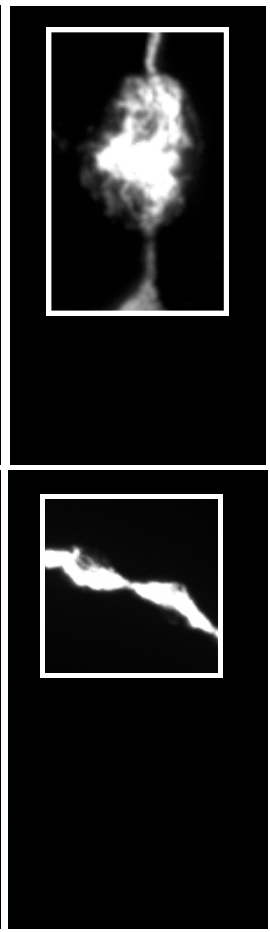

.

C
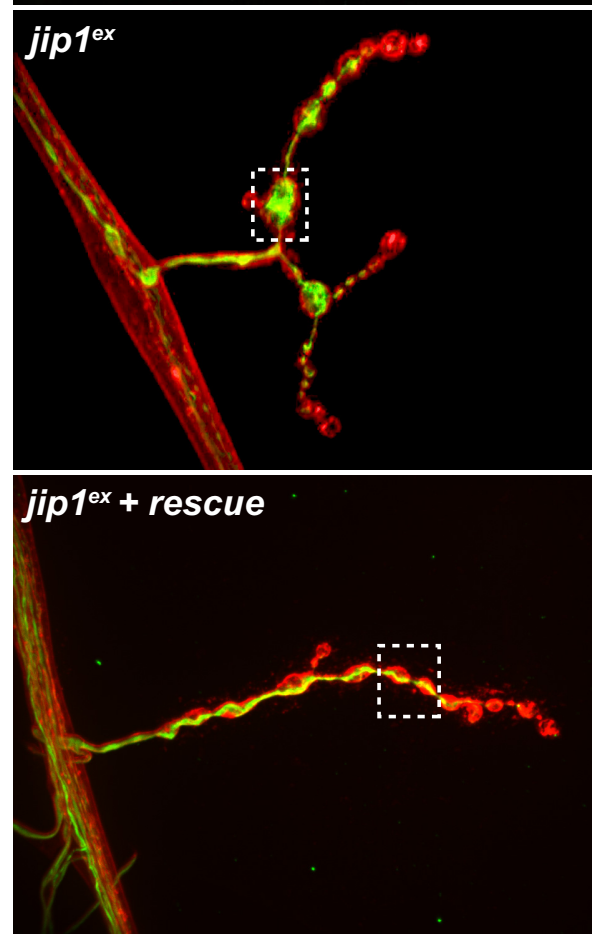

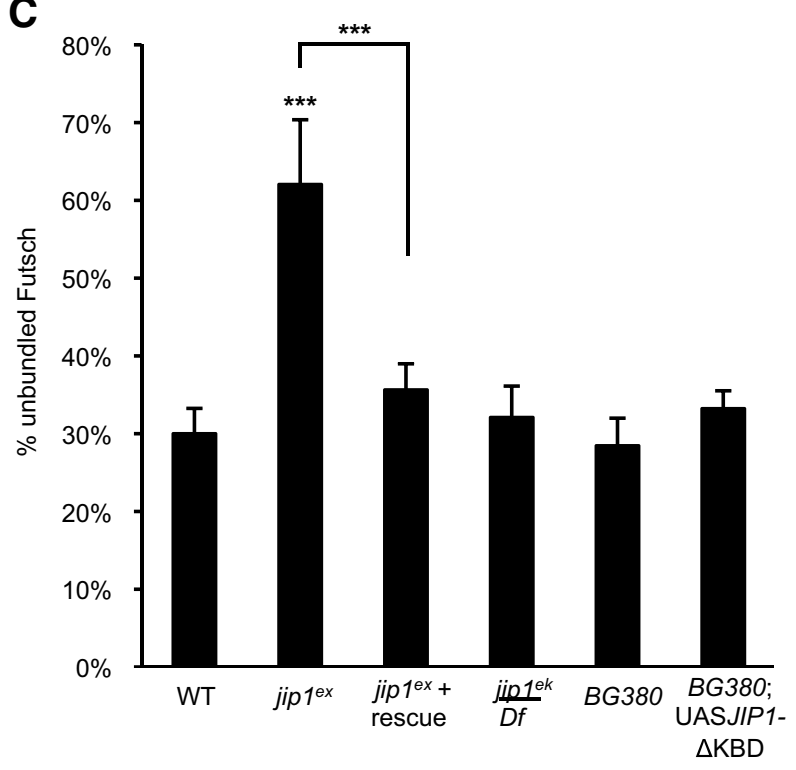

Figure 3. JPP1 is required for microtubule organization and stability. $A$, WT, jip $7^{\text {ex }} / j i p 7^{\text {ex }}$, and jip $7^{e x}$ genomic rescue synapses immunostained with HRP (red) and Futsch (green). Although microtubules normally appear bundled within WT boutons, in the enlarged boutons $(\geq 5 \mu \mathrm{m})$ of jip 1 mutants, splaying of the microtubules is observed. This unbundling of the microtubules can be rescued with the expression of one copy of a genomic JIP1 transgene. $\boldsymbol{B}$, Acetylated tubulin (green) is localized in a tightly bundled cable that extends through the NMJ synapse of WT animals. Within enlarged boutons of $j i p 1$ mutants, acetylated tubulin has a discontinuous, punctate pattern, which can be rescued with one copy of a genomic JIP1 transgene. C, Quantification of the percentage of unbundled Futsch for different genotypes (see Materials and Methods). C, Error bars indicate mean \pm SEM. ${ }^{* *} p \leq 0.0001$. Scale bars, $10 \mu \mathrm{m}$.

Inhibition of JNK and Fos, by either strong expression of dominant-negative $(\mathrm{DN})$ transgenes $\left(\mathrm{JNK}^{\mathrm{DN}}\right.$ and $\mathrm{Fos}^{\mathrm{DN}}$ ) or RNAi targeted knockdown, did not result in any changes to bouton morphology (Fig. 5F), suggesting that other factors may function downstream of Wnd and JIP1 at synapses.

Therefore, we tested the role of the p38 MAPKs, because it has been reported previously that Wnd/DLK signals through p38 in C. elegans (Hammarlund et al., 2009; Nix et al., 2011). Also, JIP

(Figure legend continued.) [and a greater number of oversized (data not shown)] boutons compared with control animals. jip $1^{\text {ek4 }}$ synapses look similar to WT animals. jip3 synapses display smaller boutons compared with controls. Expression of the jip1 $\triangle K B D$ transgene lacking the kinesin binding domain (UAS-JIP1 $\triangle K B D$ ) did not result in an enlarged bouton phenotype. C, Rescue of the jip $1^{\text {ex }}$ bouton phenotype. Neuronal expression of a JIP1 transgene results in synapses with slightly larger boutons compared with WT animals, but rescues the enlarged boutons observed in jip $7^{\text {ex }}$ mutants. D, Quantification of maximum bouton diameter in second-instar larvae. Boutons are enlarged in $j i p 1^{e x}$ and $j i p 1^{e x} / D$ f mutants even at this earlier developmental stage. Error bars indicate mean \pm SEM. ${ }^{*} p \leq 0.01,{ }^{* *} p \leq 0.001,{ }^{* *} p \leq 0.0001$. Scale bars, $10 \mu \mathrm{m}$. family members have been shown to scaffold p38 MAPKs as well as JNK MAPKs in vertebrate cells (Schoorlemmer and Goldfarb, 2001; Buchsbaum et al., 2002; Lee et al., 2002; Kelkar et al., 2005). In Drosophila, the two p38 MAPK genes $p 38 a$ and $p 38 b$ (Han et al., 1998; Adachi-Yamada et al., 1999; Suzanne et al., 1999; Zhuang et al., 2006), have been extensively studied in relation to stress (Inoue et al., 2001; Craig et al., 2004; Sano et al., 2005; Cully et al., 2010; Vrailas-Mortimer et al., 2011) and the fly immune system (Han and Ip, 1999; Davis et al., 2008; Ha et al., 2009; Shinzawa et al., 2009). p38 has also been shown to participate in developmental processes, including axial polarity during oogenesis, intestinal stem cell proliferation and differentiation, and $d p p$ regulated stem cell morphogenesis (Adachi-Yamada et al., 1999; Suzanne et al., 1999; Park et al., 2009).

Using a null mutation of $p 38 a\left(p 38 a^{\Delta}\right)$ that is deleted for the entire $p 38 a$ locus (Craig et al., 2004), we found no significant role for p38a in the regulation of bouton size (Fig. 5B). However, additional genetic interactions with Wnd (Fig. 6) still imply a 

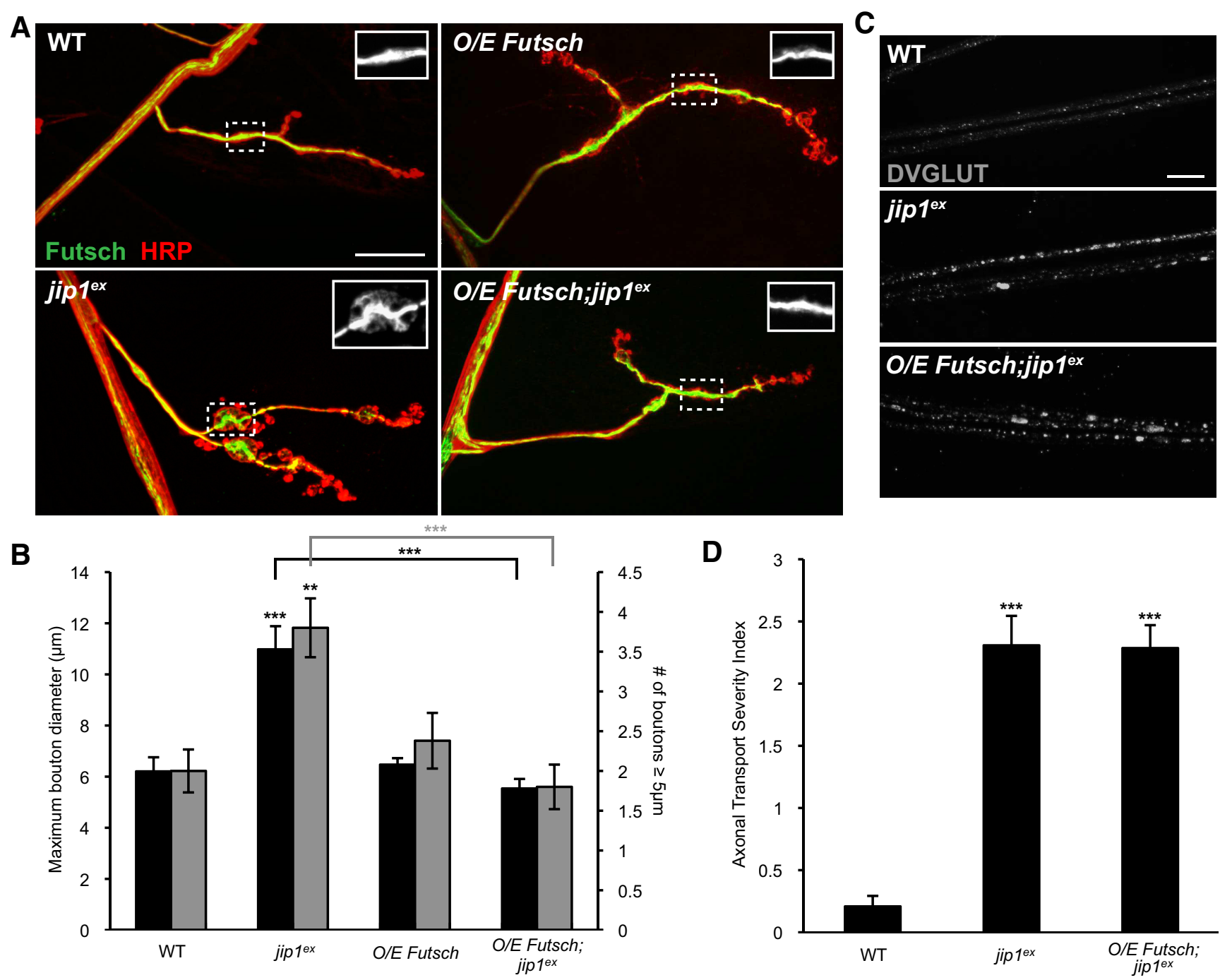

B
D

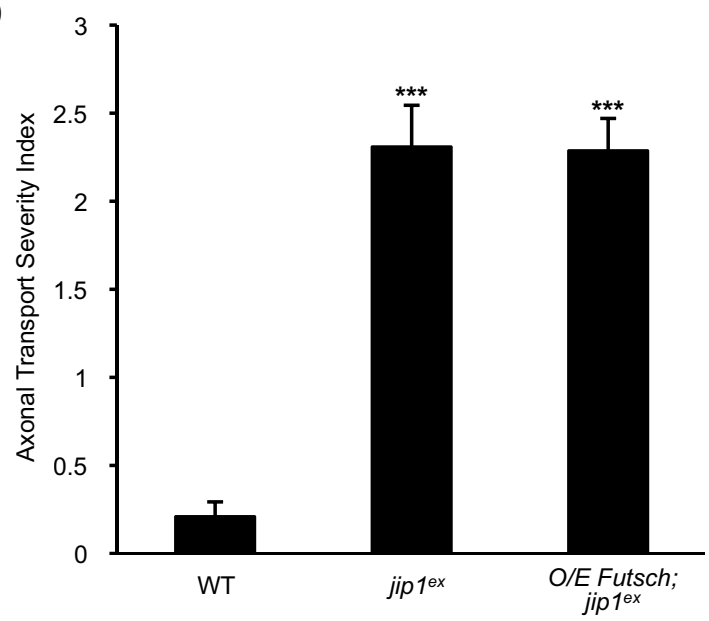

Figure 4. Overexpression of Futsch rescues the jip1 synaptic defect but not the axonal transport defect. $A$, Representative muscle 4 NMJs were costained with anti-HRP (red) and anti-Futsch

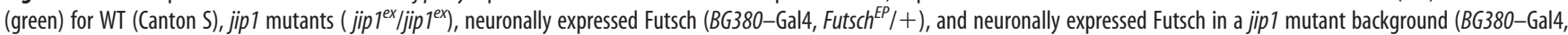
Futsch $\left.h^{E P} /+; j i p 7^{e x} / j i p 7^{e x}\right)$. B, Quantification of maximum bouton diameter and number of boutons $\geq 5 \mu \mathrm{m}$. Neuronal expression of Futsch in a jip 1 mutant background can rescue the enlarged bouton phenotype. Neuronal expression of Futsch alone does not alter the synaptic bouton size. C, Peripheral nerves from third-instar larvae immunostained with DVGLUT. Overexpression of Futsch in a jip 1 mutant background is unable to rescue the axonal transport defect. $\boldsymbol{D}$, Quantification of the axonal transport severity index. There is no difference in axonal trafficking defects between $j i p 1$ mutants and jip 1 mutants with Futsch overexpressed in neurons. Error bars indicate mean \pm SEM. ${ }^{* *} p \leq 0.001,{ }^{* * *} p \leq 0.0001$. Scale bar, $10 \mu \mathrm{m} .0 / \mathrm{E}, 0$ verexpressed.

function for $\mathrm{p} 38 \mathrm{a}$ at the synapse (discussed further below). To examine the role of $\mathrm{p} 38 \mathrm{~b}$, we used two different alleles: (1) a null allele that removes most of the coding region $\left(p 38 b^{\Delta}\right)$ (VrailasMortimer et al., 2011) and (2) a transposon insertion allele $\left(p 38 b^{K G 01337}\right)$. In contrast to $p 38 a, p 38 b$ mutants displayed a prominent bouton morphology defect that resembled both jip1 and $w n d$ mutants in the increase in maximum bouton size (Fig. $5 A, B$ ), as well as the number of boutons exceeding $5 \mu \mathrm{m}$ (Fig. $5 A$ and data not shown). Double mutants for $p 38 a^{\Delta}$ and $p 38 b^{\Delta}$ did not enhance this phenotype. Inhibition of p38b, by either RNAi knockdown (Fig. $5 D, E$ ) or the expression of a DN allele $\left(\mathrm{p} 38 \mathrm{~b}^{\mathrm{DN}}\right)$, specifically in neurons also resulted in enlarged boutons (Fig. $5 F$ ), indicating a cell-autonomous role for $\mathrm{p} 38 \mathrm{~b}$ in regulating bouton morphology. The loss of $p 38 b$ also resulted in an increase in the overall percentage of unbundled Futsch (Fig. $5 A, G$ ), similar to what was observed in jip1 mutants (Fig. $3 C$ ). These findings signify a new role for $\mathrm{p} 38 \mathrm{~b}$ in regulating bouton morphology and microtubule structure at Drosophila synapses.
To further probe the hypothesis that Wnd and p38 regulate synaptic boutons through a common pathway, we asked whether $w n d$ and $p 38 b$ genetically interact. Figure $5 C$ shows that, although animals missing one copy of either $w n d$ or $p 38 b$ have no phenotype, animals missing one copy of both wnd and $p 38 b$ display enlarged boutons (and misregulated cytoskeleton; data not shown) similar to complete loss-of-function mutations in wnd and $p 38 b$. Additional genetic interactions are described further below.

JIP1 and p38 mediate synaptic growth and nuclear signaling downstream of Hiw

One of the most striking documented regulators of synaptic growth is Hiw, a conserved E3 ubiquitin ligase (Schaefer et al., 2000; Wan et al., 2000; Zhen et al., 2000). At the Drosophila NMJ, mutations in hiw cause a dramatic increase in the number of synaptic boutons and branches at the larval NMJ (Wan et al., 2000; Collins et al., 2006; Fig. 6A,B). This synaptic overgrowth phenotype is caused by an increased activity of Wnd, whose levels 

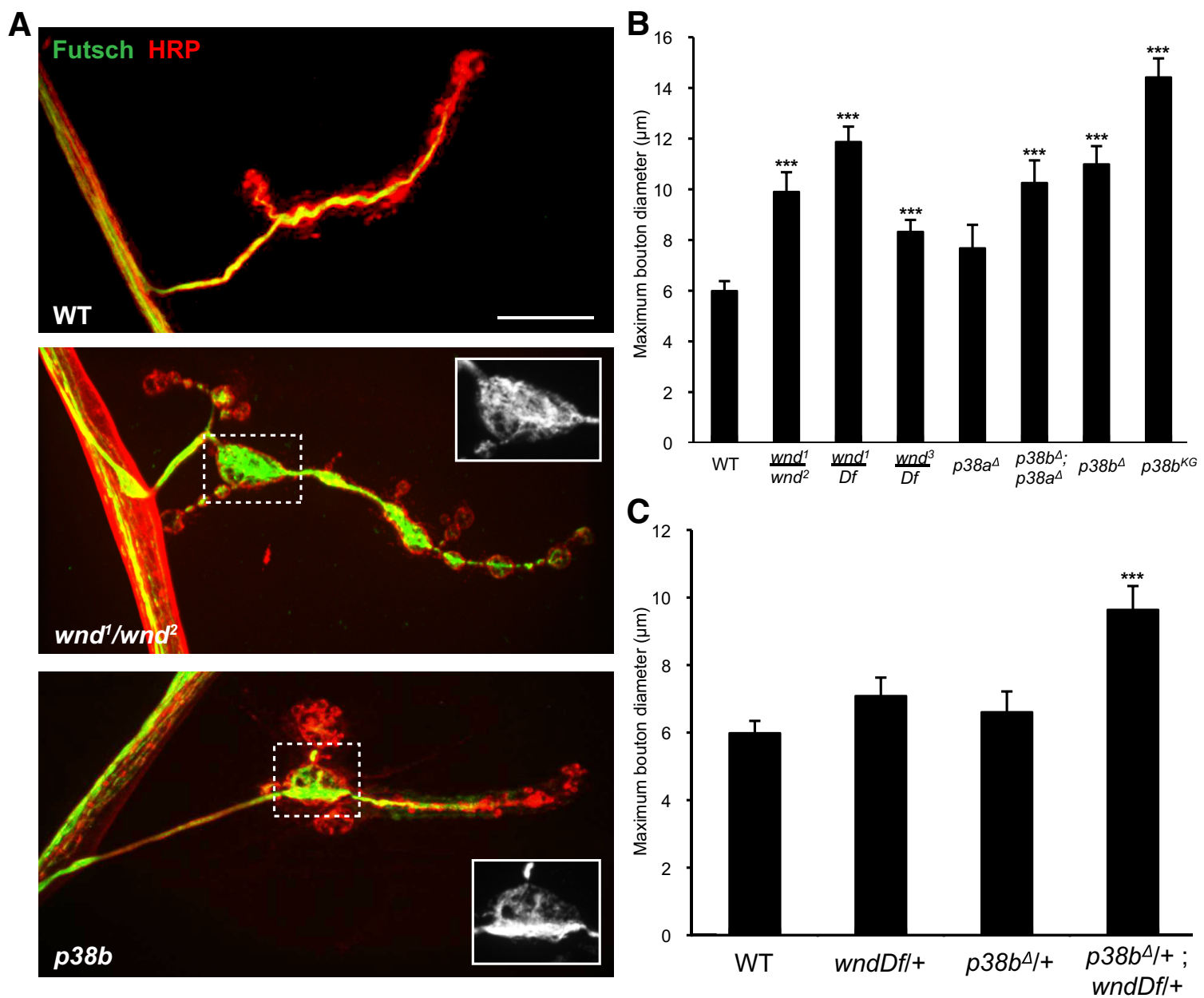

D

E

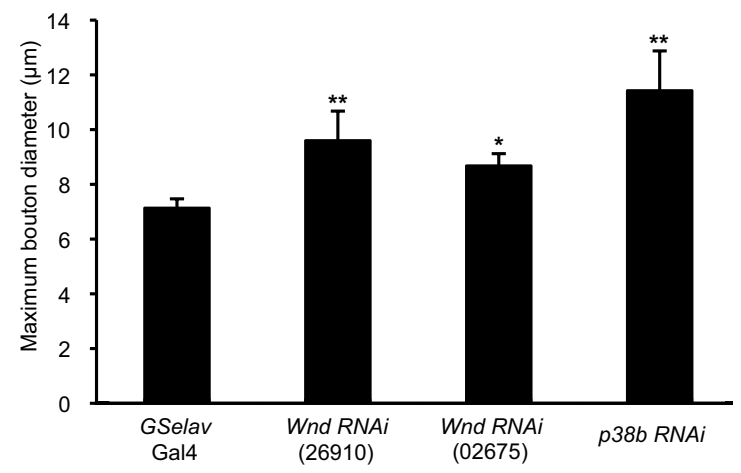

$\mathbf{F}$
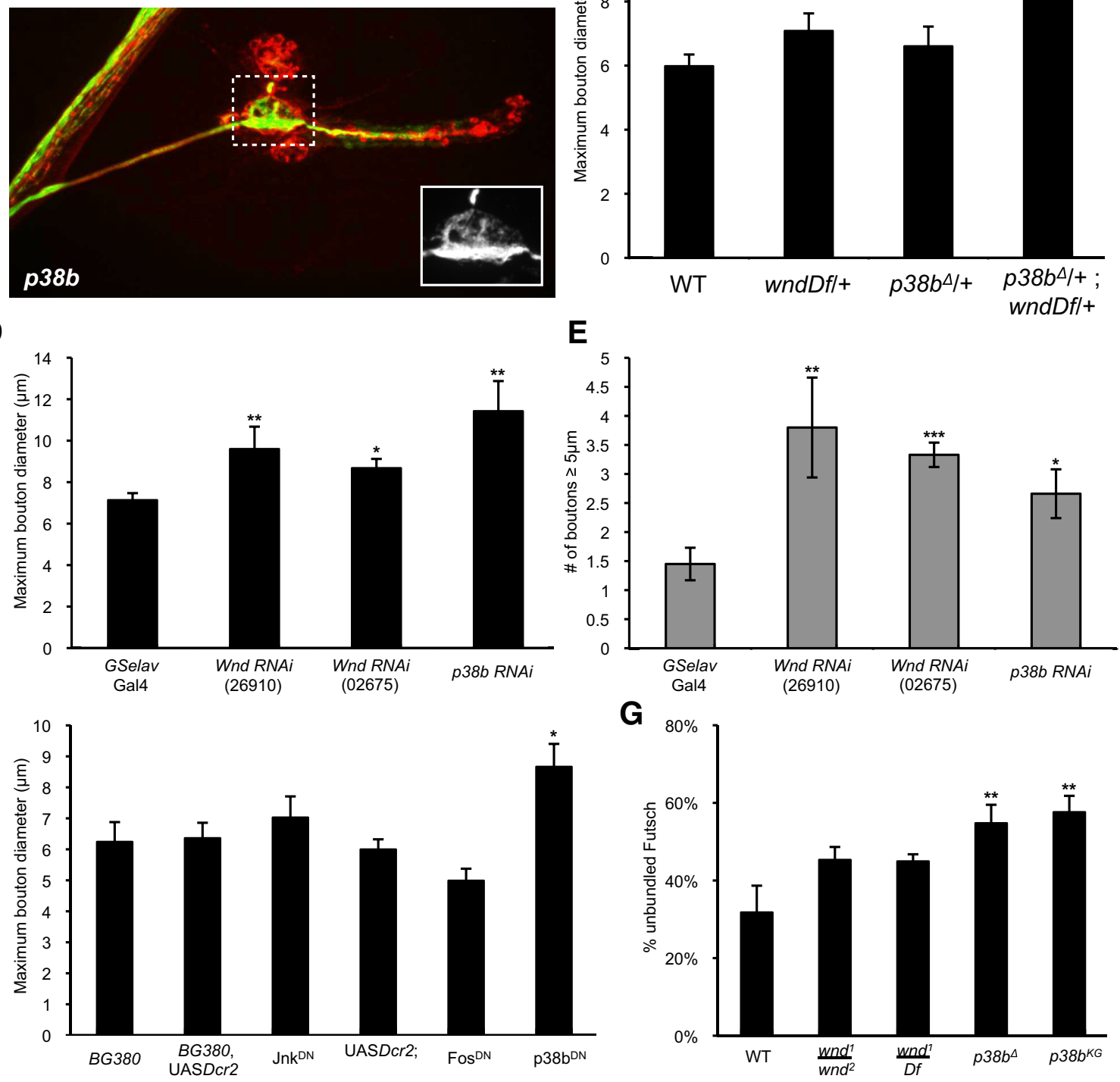

Figure 5. Regulation of synaptic morphology and cytoskeleton by the Wnd/DLK MAPKKK and p38b MAPK. A, WT (Canton S), wnd mutant (wnd $/$ wnd ${ }^{2}$ ), and $p 38 b$ mutant ( $\left.p 38 b^{\Delta}\right)$ muscle 4 synapses immunostained with HRP (red) and Futsch (green). Both wnd and $p 38 b$ mutants display enlarged boutons compared with WT animals. In the large boutons, Futsch staining becomes unbundled (see inset). $\boldsymbol{B}-\boldsymbol{F}$, Quantification of maximum bouton diameter and number of boutons $\geq 5 \mu \mathrm{m}$. $\boldsymbol{B}$, Three different allelic combinations for wnd display an increase (Figure legend continues.) 
in axons and synapses is regulated by Hiw (Collins et al., 2006). We found that this synaptic gain-of-function phenotype for wnd could be suppressed by mutations in either jip 1 or $p 38 b$ (Fig. $6 A, B)$. In addition, $p 38 a$ mutants, which did not have a loss-offunction phenotype on their own at the NMJ (Fig. 5B), suppressed the hiw synaptic overgrowth phenotype (Fig. 6B). These observations revise a previous conclusion based on DN constructs for p38 (Collins et al., 2006) and imply a role for both p38a and $\mathrm{p} 38 \mathrm{~b}$ in synaptic growth. This role may function independently of the regulation of microtubules and bouton size. Alternatively, the function of $\mathrm{p} 38 \mathrm{a}$ may be specific to situations when Wnd signaling levels are high. These findings further support the model that JIP1 and the p38 MAPK function together with Wnd to regulate the morphology of the presynaptic axon terminus.

Of note, the genetic interactions revealed reciprocal suppression of phenotypes for hiw, jip 1, and p38: not only did mutations in either jip1 or $p 38$ suppress the hiw synaptic overgrowth phenotype (Fig. $6 A, B$ ), mutations in hiw also suppressed the enlarged bouton (Fig. 6A,C) and Futsch unbundling (data not shown) phenotypes of jip1 and p38 mutants. Similarly, overexpression of Wnd also suppressed the bouton morphology phenotype of jip1 mutants (Fig. 6D). This suppression interaction is consistent with the hypothesized role of JIP1 as a scaffold for Wnd signaling: its function in assisting the activation of Wnd can be overcome if Wnd levels are increased. However, the suppression of $p 38 b$ by hiw suggests that the relationships are more complex than a simple linear pathway. One possibility is that, when Wnd levels are high, then p38a can substitute for p38b. Overall, these genetic interactions suggest that Wnd, JIP1, and p38 function together to regulate synaptic morphology.

Previous studies of Hiw indicate that the synaptic overgrowth phenotype is mediated by a Wnd-regulated nuclear signaling cascade, which is overactive in hiw mutants. This leads to a strong induction of the $p u c-$ lacZ reporter (Xiong et al., 2010; Fig. 6E), which also becomes induced after axonal injury (Xiong et al., 2010; Fig. 1D). In both injured neurons and hiw mutants, the induction of puc-lacZ is mediated by Wnd (Xiong et al., 2010). Although jip1 is not required for the induction of $p u c-$ lacZ after injury (Fig. $1 D$ ), we found that it is partially required for the induction of puc-lacZ in hiw mutants (Fig. 6E). The differences in requirement for JIP1 suggest that there may be multiple mechanisms for activating Wnd in neurons. Axonal injury activates Wnd signaling through a mechanism that does not require JIP1 (Fig. 1D). In contrast, in uninjured neurons, Wnd regulates a signaling pathway that controls the structure of synaptic boutons, and this pathway is significantly diminished in the absence of JIP1 (Fig. 6E).

\footnotetext{
(Figure legend continued.) in maximum bouton diameter and the number of boutons $\geq 5$ $\mu \mathrm{m}$ (data not shown). p38a null mutants do not have a synaptic morphology defect. $p 38 b$ mutants have an enlarged bouton phenotype that is similar to both wnd and jip 1 mutants. $p 38 a$ and $p 38 b$ double mutants display enlarged boutons similar to the $p 38 b$ null mutant alone. $C$, Trans-heterozygous genetic interaction between wndDf/ + and $p 38 b^{\Delta} /+. \boldsymbol{D}, \boldsymbol{E}$, Neuronal expression of either wnd or $p 38 b$ RNAi knockdown constructs resulted in animals with significantly larger boutons compared with control animals (GSelav-Gal4/+). $\boldsymbol{F}$, Neuronal expression of either DN transgenes or RNAi knockdown of JNK or Fos does not result in animals that have larger boutons. Expression of a DN transgene for $p 38 \mathrm{~b}$ resulted in animals with enlarged boutons. G, Quantification of the percentage of unbundled Futsch. Both $p 38 b$ null and $p 386^{K G 01337}$ insertion animals have a significant increase in the amount of unbundled Futsch. wnd mutants display unbundled Futsch in large boutons, but the total amount of unbundled Futsch is unchanged compared with controls. Error bars indicate mean \pm SEM. ${ }^{*} p \leq 0.01,{ }^{* *} p \leq 0.001$, ${ }^{* * *} p \leq 0.0001$. Scale bar, $10 \mu \mathrm{m}$.
}

\section{Wnd regulates synaptic structure and injury responses} through independent signaling mechanisms

Our findings support the model that Wnd regulates multiple functions in neurons via independent downstream signaling pathways. To further test this model, we asked whether p38a and p38b, which are required for the synaptic roles of Wnd (Fig. 6), are required for axonal transport, injury signaling, and axonal regeneration after injury. In contrast to $w n d, p 38 a^{\Delta}$ and $p 38 b^{\Delta}$, as well as $p 38 a^{\Delta}, p 38 b^{\Delta}$ double mutants, displayed only mild defects in axonal transport (Fig. $7 A$ ). Also in contrast to Wnd, neither $\mathrm{p} 38 \mathrm{a}$ nor $\mathrm{p} 38 \mathrm{~b}$ are required for the induction of $p u c-l a c Z$ after injury (Fig. $7 B$ ). Similarly, mutations in $p 38 a$ or $p 38 b$ did not impair the ability of injured axons to form new axonal branches after injury (Fig. 7C,D). This contrasts to the essential roles for Wnd and JNK in controlling this regenerative sprouting response to injury (Xiong et al., 2010). These findings imply that different downstream functions of Wnd depend on different and functionally separable downstream mechanisms.

\section{Discussion}

\section{Requirement for the JIP1 scaffold reveals independent pathways downstream of Wnd}

Wnd/DLK signaling regulates multiple processes in neurons, including axonal transport, neuronal migration, developmental apoptosis, axonal regeneration, axonal degeneration, and cell death after injury (Hirai et al., 2006; Bloom et al., 2007; Horiuchi et al., 2007; Chen et al., 2008; Hammarlund et al., 2009; Miller et al., 2009; Yan et al., 2009; Xiong et al., 2010; Ghosh et al., 2011; Itoh et al., 2011; Xiong and Collins, 2012; Watkins et al., 2013; Welsbie et al., 2013). Our data suggest the existence of a new role for Wnd in regulating the structure of synaptic microtubules. A major question is how a single MAPKKK can achieve these different and often dichotomous functions in both neuronal development and maintenance. We find that the role of Wnd in synaptic development can be functionally separated from its role in responding to axonal injury. The regulation by Wnd of synaptic development requires both the scaffolding protein JIP1 as well as the downstream MAPK p38. In contrast, p38 is not required for the role of Wnd in injury signaling and the promotion of new axonal growth after injury. Therefore, in Drosophila motoneurons, Wnd regulates at least two independent pathways: (1) one that promotes responses to axonal damage and (2) another that regulates synaptic morphology in uninjured neurons. JIP1 plays an essential role in the second pathway but not the first (Fig. 7E).

It is intriguing to note that jip3/Syd mutants have a complementary phenotype to jip1 mutants: JIP3 is required for injury signaling but not for regulating synaptic microtubules. The model that JIP3 scaffolds the injury signaling pathway is supported by studies of vertebrate JIP3/Syd, which interacts with phosphorylated JNK in axons, and is retrogradely transported in response to axonal injury (Cavalli et al., 2005). Therefore, the JIP1 and JIP3 scaffolds can mediate independent roles for Wnd through distinct downstream signaling mechanisms.

\section{Wnd/DLK regulates synaptic microtubules via $\mathrm{p} 38$}

A number of studies of Wnd/DLK homologs in both C. elegans and vertebrate neurons suggest that this kinase may regulate the microtubule cytoskeleton via both JNK (Hirai et al., 2002; Eto et al., 2010; Hirai et al., 2011) and p38 (Lewcock et al., 2007; Bounoutas et al., 2011; Ghosh-Roy et al., 2012) signaling, both of which are known to have microtubule-associated substrates, including Tau, MAP1B, MAP2B, and stathmin (Gelderblom et al., 2004; Corrêa and Eales, 2012). Moreover, the JIP1 scaffold is 

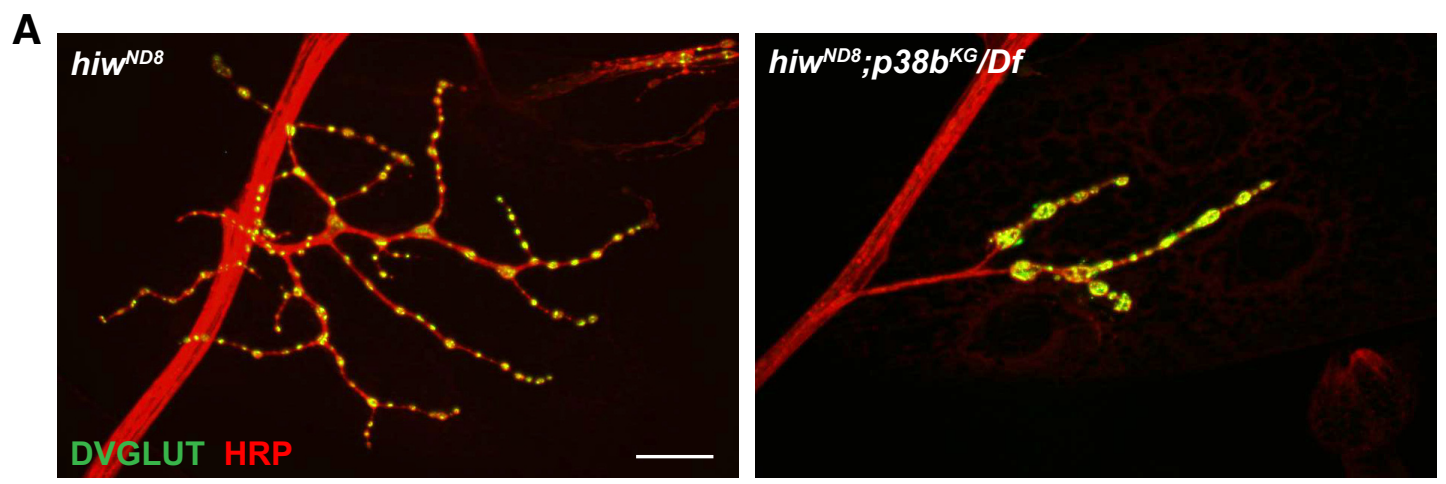

B

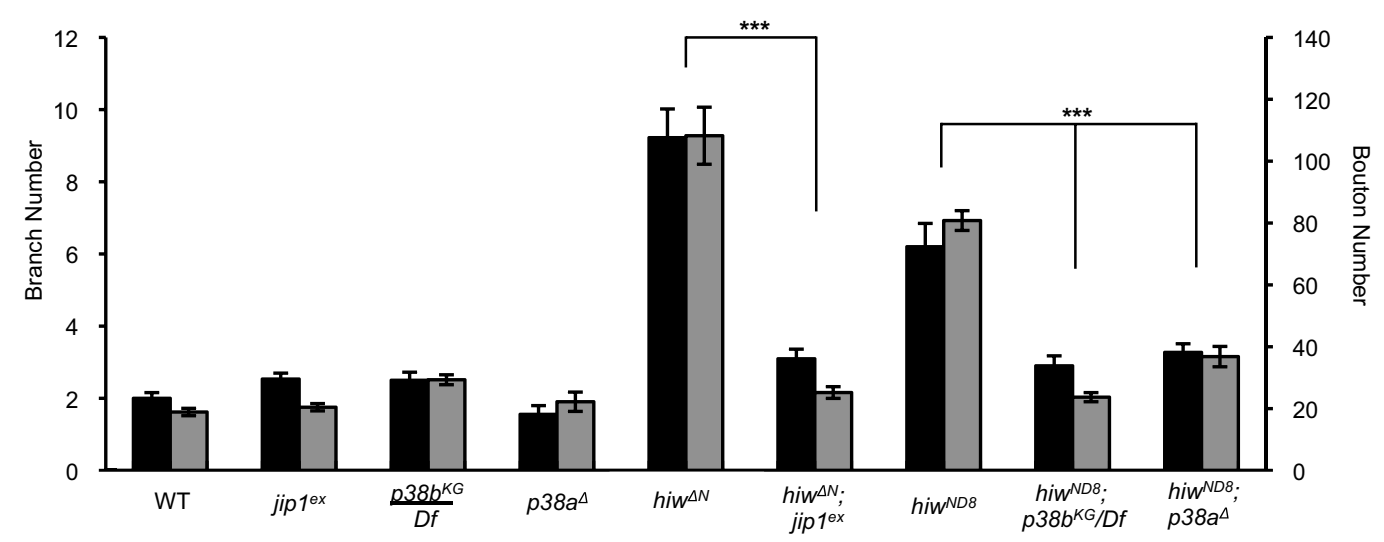

C

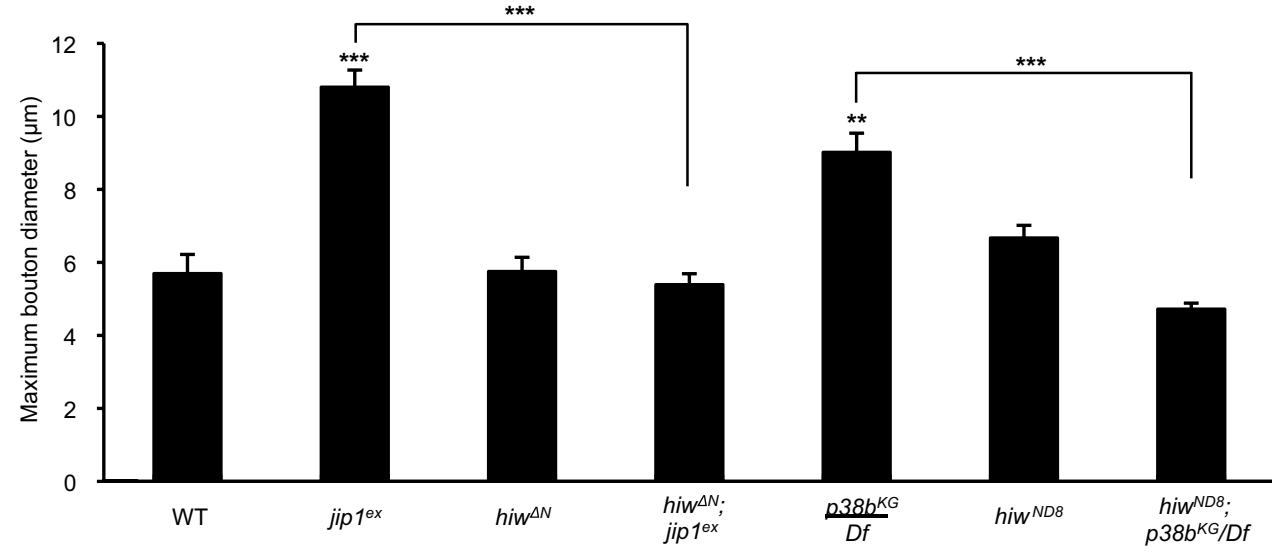

D

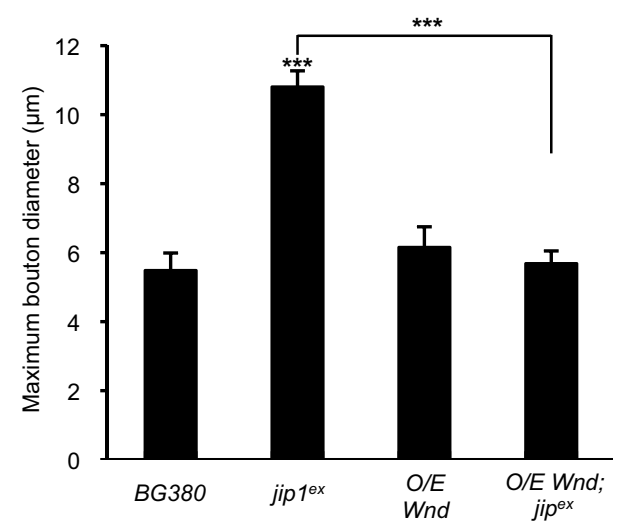

E

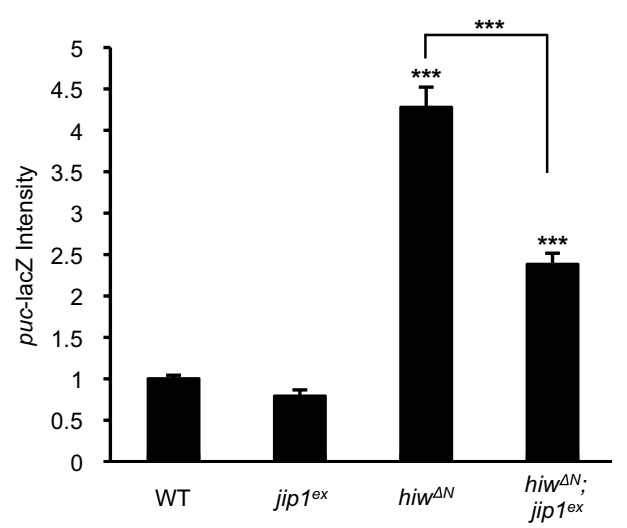

Figure 6. Wnd regulates synaptic structure via the $\mathrm{p} 38$ MAPK and JP1 1 scaffold. $A$, NMJ synapses at muscle 4 stained with the neuronal membrane marker HRP (red) and synaptic vesicle marker DVGLUT (green) of hiw $\left(\right.$ hiw ${ }^{N D 8}$ ) mutants and double mutants for hiw and $p 38 b\left(\right.$ hiw $^{N D 8} ; p 38 b^{K G} / D f$ ). B, Quantification of suppression of the hiw synaptic morphology phenotype including branch number (black bars) and bouton number (gray bars). p38a, $p 38 b$, and jip 1 can all rescue the synaptic overgrowth phenotype of hiw mutants. $C, D, Q$ uantification of suppression of maximum bouton diameter. hiw and neuronally expressed Wnd (BG380-Gal4;UAS-wnd/+) can rescue the enlarged bouton phenotype in jip 1 and $p 38 b$ ( $p 38 b^{K G} / D f$ ) mutants. E, Quantification of $p$ uC-lacZ.jip 1 is required for the induction of puc-lacZ in hiw mutants. Error bars indicate mean \pm SEM. ${ }^{* *} p \leq 0.001,{ }^{* * *} p \leq 0.0001$. Scale bar, $10 \mu \mathrm{m} .0 / \mathrm{E}, 0$ verexpressed. 
A

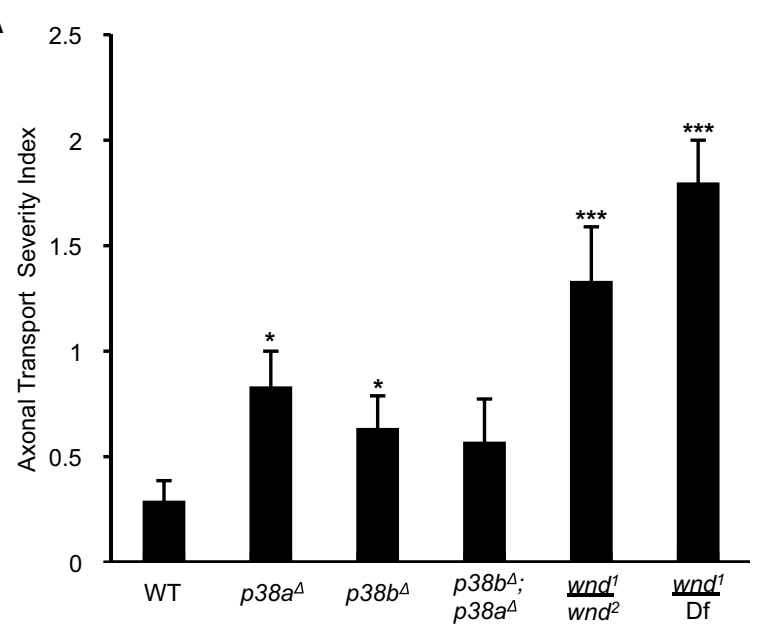

C

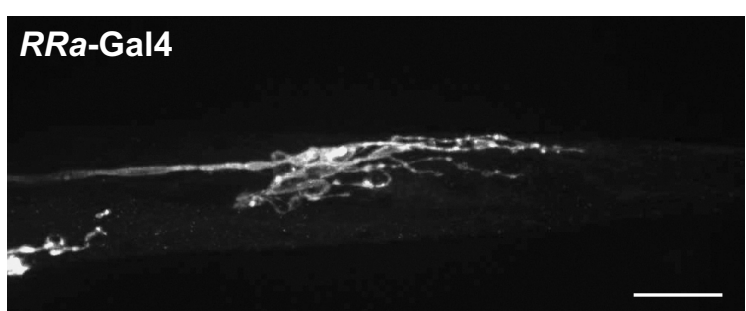

$p 38 a^{\Delta}$

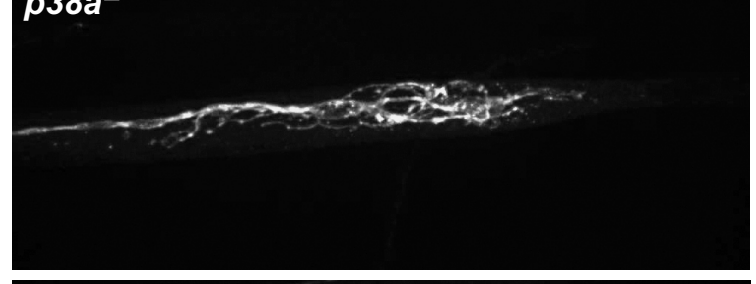

\section{$w n d^{1 / w n d^{2}}$}

D

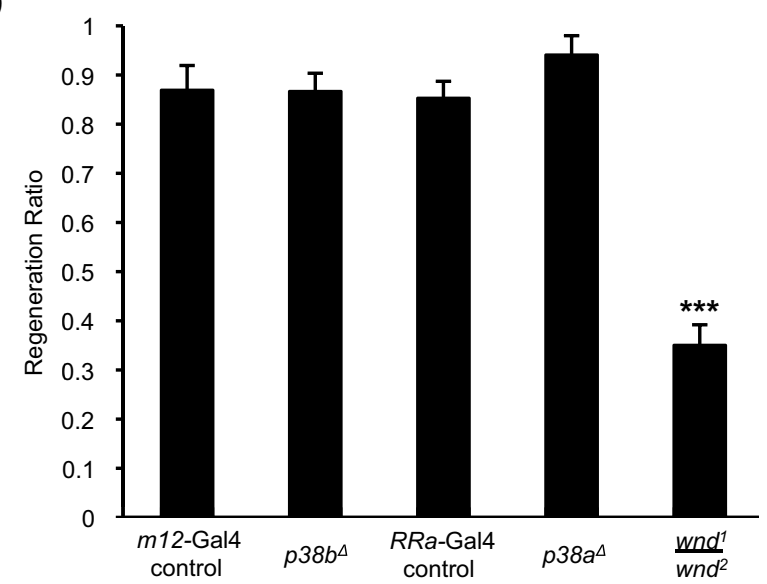

B

E
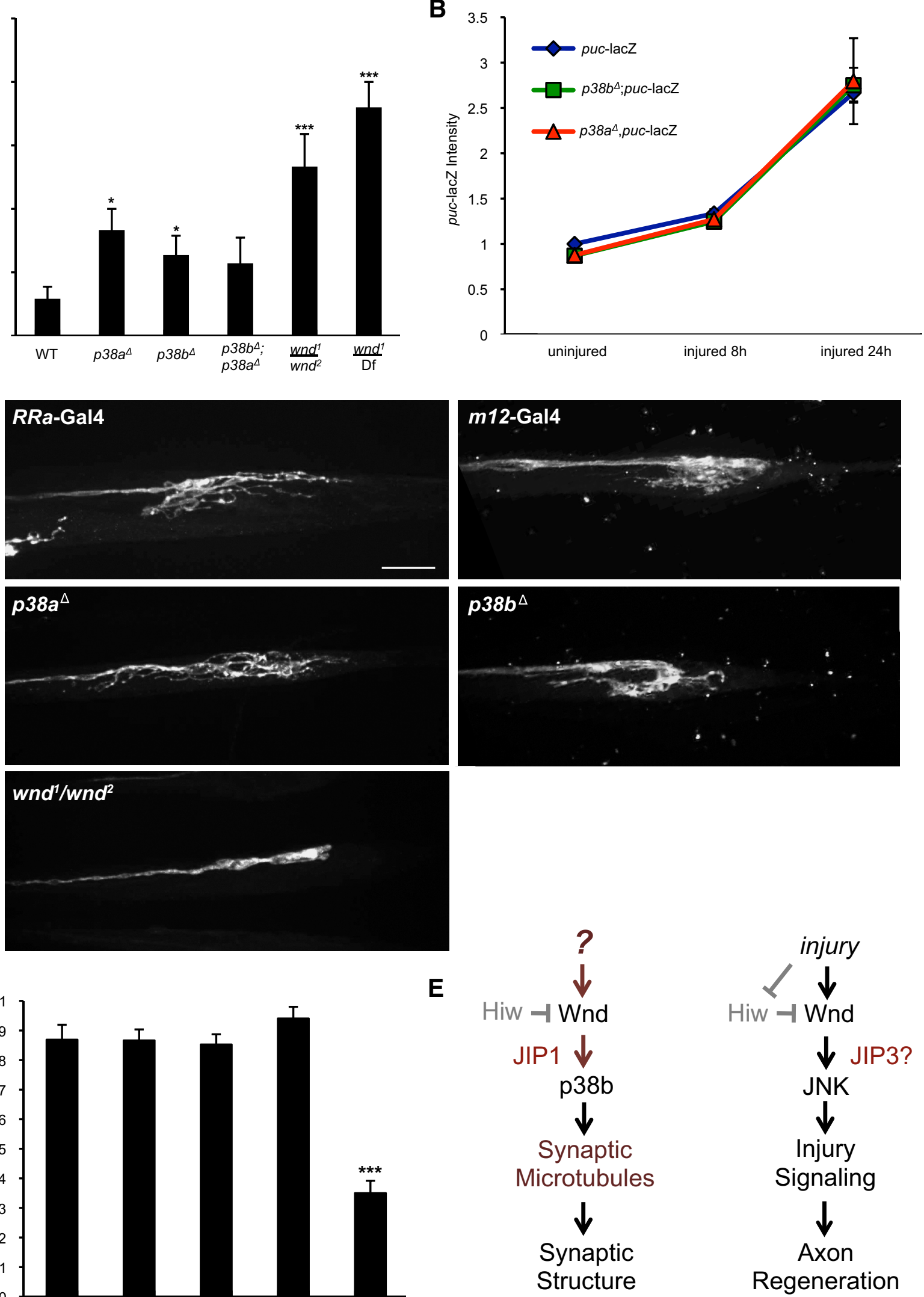

Figure 7. Different downstream actions of Wnd require different downstream signaling components. $A$, Quantification of axonal transport severity index. $p 38 a$ and $p 38 b$ null mutants display very minor, but statistically significant, defects in axonal transport. B, Quantification of puc-lacZ intensity after injury. Both $p 38 a$ and $p 38 b$ mutants show increased levels of puc-lacZ intensity similar to controls. C, Axons are labeled by driving expression of UAS-mCD8 -RFP with RRa(eve)-Gal4 or UAS-mCD8 -GFP with m12-Gal4. In WT animals, the proximal stump (Figure legend continues.) 
known to play an important role in the regulation of microtubules by MAPK signaling (Goedert et al., 1997; Reynolds et al., 1997a,b; Chang et al., 2003; Gdalyahu et al., 2004; Tararuk et al., 2006). Although the direct downstream effectors of Wnd/DLKs actions on synaptic microtubules remains to be fully characterized, important functional consequences may include the facilitation of axon formation during the early stages of neuronal polarization (Eto et al., 2010; Hirai et al., 2011), regulation of a transcriptional response to depolymerized microtubules (Bounoutas et al., 2011), and regulation of microtubule dynamics within injured axons (Ghosh-Roy et al., 2012), which are important for an injured axon to initiate regenerative growth (GordonWeeks, 2004; Erez et al., 2007; Stone et al., 2010; Chen et al., 2012; Hur et al., 2012).

In C. elegans, p38 appears to play a role in all the known functions of DLK, including both synapse formation (Nakata et al., 2005; Grill et al., 2007) and regeneration after injury (Hammarlund et al., 2009; Yan et al., 2009; Nix et al., 2011). In contrast, we observed that, in Drosophila, p38b mediates a synaptic role for Wnd, but $\mathrm{p} 38 \mathrm{a}$ and $\mathrm{p} 38 \mathrm{~b}$ are not required for injury signaling and axonal sprouting after injury. Although downstream signaling pathways and the mechanisms of activation may diverge in evolution, we acknowledge that the assay for the requirement of p38 in axonal regeneration is more stringent in C. elegans than in our sprouting assay after nerve crush in Drosophila, because the sprouting axons in Drosophila nerves fail to reach their final target (Xiong et al., 2010). Therefore, it remains possible that $\mathrm{p} 38$ will be required for steps in axonal regeneration that could not be addressed in our current assay. The puc-lacZ induction likely reports a specific aspect of Wnd pathway activation, and this is useful for teasing apart multiple downstream events.

In C. elegans, an additional MAPKKK, mixed-lineage kinase-1 (MLK-1), functions in parallel to DLK to promote axonal regeneration (Nix et al., 2011). The Drosophila homolog of MLK-1, Slpr (Stronach and Perrimon, 2002; Sathyanarayana et al., 2003), is not required for the induction of $p u c-$ lacZ after injury (Xiong et al., 2010), but this does not rule out other potential functions for Slpr in neurons. Because the synaptic phenotype of jip1 mutants is more severe than the phenotype of $w n d$ mutants, a potential role for additional MAPK regulators, such as Slpr, in the regulation of synaptic microtubules should also be considered.

\section{Separating roles in signaling from roles in axonal transport}

The JIP scaffolding proteins interact with both the kinesin-I and dynein motors (Verhey et al., 2001; Cavalli et al., 2005; Horiuchi et al., 2005; Kelkar et al., 2005; Nguyen et al., 2005; Arimoto et al., 2011; Sun et al., 2011) and may play a role in mediating the regulation of these motors by MAPK signaling (Morfini et al., 2006, 2009; Stagi et al., 2006; Horiuchi et al., 2007). Indeed, lossof-function studies of JIP1/APLIP1 and JIP3/Syd suggest that both play roles in axonal transport (Bowman et al., 2000; Byrd et al., 2001; Taru et al., 2002; Horiuchi et al., 2005). Because JIPs are physically carried by kinesin and dynein motors, the converse

\footnotetext{
(Figure legend continued.) forms extensive new branches by $15 \mathrm{~h}$ after injury. Sprouting after injury is inhibited in a wnd mutant background $\left(w n d^{1} / w n d^{2}\right)$. New sprouting forms at the proximal stumps in both $p 38 b$ and $p 38 a$ mutants similar to control axons. D, Quantification of regeneration ratio $15 \mathrm{~h}$ after injury. The fraction of injured axons that displayed sprouting was measured while blinded to the genotype. $\boldsymbol{E}$, Model: Wnd promotes the development of synaptic structure and injury signaling through separate pathways that differ in their requirement for p38b and the JIP1 scaffolding protein. Error bars indicate mean \pm SEM. ${ }^{*} p \leq 0.01,{ }^{* * *} p \leq$ 0.0001. Scale bar, $10 \mu \mathrm{m}$.
}

relationship may also be true: motor proteins may regulate the signaling complexes that are scaffolded by JIPs, by delivering the signaling complexes to specific subcellular locations. This appears to be the case for Wnd signaling, because the downstream cascades for both injury signaling and synaptic growth appear to depend on functional axonal transport machinery. The localization of JIP1 to the axon terminus requires Kinesin-1 (Verhey et al., 2001; Reed et al., 2006), and we propose that this localization mediates a specific role for Wnd signaling at the synapse. Conversely, the interaction of JIP3/Syd with dynein is thought to mediate retrograde signaling in response to axonal injury (Cavalli et al., 2005).

An essential role for the axonal transport machinery within neurons makes it difficult to delineate the precise function for any individual molecule involved in this process. A mutant that exhibits axonal transport defects may affect multiple signaling pathways, which may rely either directly or indirectly on the axonal transport machinery. Therefore, it is remarkable that the jip1 mutants exhibit such a specific synaptic phenotype given their axonal transport impairment. Of the many other known mutations in Drosophila that inhibit axonal transport in motoneurons, including subunits of kinesin-1, kinesin-3, dynactin, and dynein, as well as jip3/Syd, none display the enlarged bouton phenotype observed for jip1 mutants (Fig. 2A,B; Hurd and Saxton, 1996; Eaton et al., 2002; Pack-Chung et al., 2007). We were further able to dissociate a role for JIP1 signaling in synaptic development from axonal transport, because the enlarged bouton phenotype of jip 1 mutants could be suppressed independently of the axonal transport defect. Although we expect that the roles of JIP1 in both axonal transport and synaptic development are intimately linked, they can nevertheless be genetically separated.

\section{A role for Wnd/DLK in uninjured synapses}

Our studies of JIP1 have led to the discovery of a new role for Wnd signaling in regulating synaptic development via JIP1 and p38b. Previous studies in Drosophila and C. elegans have failed to detect such a function for Wnd/DLK. Instead, the previously described synaptic phenotypes were gain-of-function because of the loss of regulation by the Hiw ubiquitin ligase. Since the discovery of the role of Wnd/DLK in axonal regeneration (Hammarlund et al., 2009; Yan et al., 2009; Ghosh-Roy et al., 2010; Xiong et al., 2010; Nix et al., 2011; Shin et al., 2012; Xiong and Collins, 2012), it has been hypothesized that its main function in neurons is to detect axonal injury. The current data now suggest otherwise. JIP1 promotes the activation of a signaling cascade that specifically regulates the structure of presynaptic boutons. This further suggests that Wnd becomes activated in uninjured neurons by unknown upstream factors. Because Wnd and JIP1 can localize to presynaptic boutons (Verhey et al., 2001; Muresan and Muresan, 2005; Collins et al., 2006; data not shown), they may potentially act locally to regulate presynaptic events during synaptic development and/or plasticity. Consistent with a synaptic function for Wnd, recent behavioral studies of hiw mutants imply that the regulation of Wnd in mushroom body neurons is important for constraining the formation of long-term memories (Huang et al., 2012). An important future direction will be to identify the mechanisms that mediate and regulate the function of Wnd/JIP1/p38b signaling at synapses.

\section{Notes}

Supplemental material for this article is available at http://labs.mcdb.lsa. umich.edu/labs/collins/files/SupplementaryFigures.pdf. Figure 1 shows the quantification of the number of boutons $>5 \mu \mathrm{m}$ for different alleles 
of jip1. Figure 2 shows the quantification of the number of boutons $>5$ $\mu \mathrm{m}$ for different alleles of wnd, p38a, and $\mathrm{p} 38 \mathrm{~b}$. This material has not been peer reviewed.

\section{References}

Abe N, Cavalli V (2008) Nerve injury signaling. Curr Opin Neurobiol 18: 276-283. CrossRef Medline

Aberle H, Haghighi AP, Fetter RD, McCabe BD, Magalhães TR, Goodman CS (2002) wishful thinking encodes a BMP type II receptor that regulates synaptic growth in Drosophila. Neuron 33:545-558. CrossRef Medline

Adachi-Yamada T, Nakamura M, Irie K, Tomoyasu Y, Sano Y, Mori E, Goto S, Ueno N, Nishida Y, Matsumoto K (1999) p38 mitogen-activated protein kinase can be involved in transforming growth factor beta superfamily signal transduction in Drosophila wing morphogenesis. Mol Cell Biol 19:2322-2329. Medline

Arimoto M, Koushika SP, Choudhary BC, Li C, Matsumoto K, Hisamoto N (2011) The Caenorhabditis elegans JIP3 protein UNC-16 functions as an adaptor to link kinesin-1 with cytoplasmic dynein. J Neurosci 31:22162224. CrossRef Medline

Bloom AJ, Miller BR, Sanes JR, DiAntonio A (2007) The requirement for $\mathrm{Phr} 1$ in CNS axon tract formation reveals the corticostriatal boundary as a choice point for cortical axons. Genes Dev 21:2593-2606. CrossRef Medline

Bounoutas A, Kratz J, Emtage L, Ma C, Nguyen KC, Chalfie M (2011) Microtubule depolymerization in Caenorhabditis elegans touch receptor neurons reduces gene expression through a p38 MAPK pathway. Proc Natl Acad Sci U S A 108:3982-3987. CrossRef Medline

Bowman AB, Kamal A, Ritchings BW, Philp AV, McGrail M, Gindhart JG, Goldstein LS (2000) Kinesin-dependent axonal transport is mediated by the sunday driver (SYD) protein. Cell 103:583-594. CrossRef Medline

Buchsbaum RJ, Connolly BA, Feig LA (2002) Interaction of Rac exchange factors Tiam1 and Ras-GRF1 with a scaffold for the p38 mitogenactivated protein kinase cascade. Mol Cell Biol 22:4073-4085. CrossRef Medline

Budnik V, Koh YH, Guan B, Hartmann B, Hough C, Woods D, Gorczyca M (1996) Regulation of synapse structure and function by the Drosophila tumor suppressor gene dlg. Neuron 17:627-640. CrossRef Medline

Byrd DT, Kawasaki M, Walcoff M, Hisamoto N, Matsumoto K, Jin Y (2001) UNC-16, a JNK-signaling scaffold protein, regulates vesicle transport in C. elegans. Neuron 32:787-800. CrossRef Medline

Cavalli V, Kujala P, Klumperman J, Goldstein LS (2005) Sunday Driver links axonal transport to damage signaling. J Cell Biol 168:775-787. CrossRef Medline

Chang L, Jones Y, Ellisman MH, Goldstein LS, Karin M (2003) JNK1 is required for maintenance of neuronal microtubules and controls phosphorylation of microtubule-associated proteins. Dev Cell 4:521-533. CrossRef Medline

Chen L, Stone MC, Tao J, Rolls MM (2012) Axon injury and stress trigger a microtubule-based neuroprotective pathway. Proc Natl Acad Sci U S A 109:11842-11847. CrossRef Medline

Chen X, Rzhetskaya M, Kareva T, Bland R, During MJ, Tank AW, Kholodilov N, Burke RE (2008) Antiapoptotic and trophic effects of dominantnegative forms of dual leucine zipper kinase in dopamine neurons of the substantia nigra in vivo. J Neurosci 28:672-680. CrossRef Medline

Chen YR, Tan TH (2000) The c-Jun N-terminal kinase pathway and apoptotic signaling (review). Int J Oncol 16:651-662. Medline

Collins CA, Wairkar YP, Johnson SL, DiAntonio A (2006) Highwire restrains synaptic growth by attenuating a MAP kinase signal. Neuron 51: 57-69. CrossRef Medline

Conde C, Cáceres A (2009) Microtubule assembly, organization and dynamics in axons and dendrites. Nat Rev Neurosci 10:319-332. CrossRef Medline

Corrêa SA, Eales KL (2012) The role of p38 MAPK and its substrates in neuronal plasticity and neurodegenerative disease. J Signal Transduct 2012:649079. CrossRef Medline

Craig CR, Fink JL, Yagi Y, Ip YT, Cagan RL (2004) A Drosophila p38 orthologue is required for environmental stress responses. EMBO Rep 5:10581063. CrossRef Medline

Cully M, Genevet A, Warne P, Treins C, Liu T, Bastien J, Baum B, Tapon N, Leevers SJ, Downward J (2010) A role for p38 stress-activated protein kinase in regulation of cell growth via TORC1. Mol Cell Biol 30:481-495. CrossRef Medline
Daniels RW, Collins CA, Gelfand MV, Dant J, Brooks ES, Krantz DE, DiAntonio A (2004) Increased expression of the Drosophila vesicular glutamate transporter leads to excess glutamate release and a compensatory decrease in quantal content. J Neurosci 24:10466-10474. CrossRef Medline

Davis MM, Primrose DA, Hodgetts RB (2008) A member of the p38 mitogen-activated protein kinase family is responsible for transcriptional induction of Dopa decarboxylase in the epidermis of Drosophila melanogaster during the innate immune response. Mol Cell Biol 28:4883-4895. CrossRef Medline

Dhanasekaran DN, Kashef K, Lee CM, Xu H, Reddy EP (2007) Scaffold proteins of MAP-kinase modules. Oncogene 26:3185-3202. CrossRef Medline

Dietzl G, Chen D, Schnorrer F, Su KC, Barinova Y, Fellner M, Gasser B, Kinsey K, Oppel S, Scheiblauer S, Couto A, Marra V, Keleman K, Dickson BJ (2007) A genome-wide transgenic RNAi library for conditional gene inactivation in Drosophila. Nature 448:151-156. CrossRef Medline

Eaton BA, Fetter RD, Davis GW (2002) Dynactin is necessary for synapse stabilization. Neuron 34:729-741. CrossRef Medline

Eresh S, Riese J, Jackson DB, Bohmann D, Bienz M (1997) A CREB-binding site as a target for decapentaplegic signalling during Drosophila endoderm induction. EMBO J 16:2014-2022. CrossRef Medline

Erez H, Malkinson G, Prager-Khoutorsky M, De Zeeuw CI, Hoogenraad CC, Spira ME (2007) Formation of microtubule-based traps controls the sorting and concentration of vesicles to restricted sites of regenerating neurons after axotomy. J Cell Biol 176:497-507. CrossRef Medline

Eto K, Kawauchi T, Osawa M, Tabata H, Nakajima K (2010) Role of dual leucine zipper-bearing kinase (DLK/MUK/ZPK) in axonal growth. Neurosci Res 66:37-45. CrossRef Medline

Fan G, Merritt SE, Kortenjann M, Shaw PE, Holzman LB (1996) Dual leucine zipper-bearing kinase (DLK) activates p46SAPK and p38mapk but not ERK2. J Biol Chem 271:24788-24793. CrossRef Medline

Fujioka M, Lear BC, Landgraf M, Yusibova GL, Zhou J, Riley KM, Patel NH, Jaynes JB (2003) Even-skipped, acting as a repressor, regulates axonal projections in Drosophila. Development 130:5385-5400. CrossRef Medline

Gdalyahu A, Ghosh I, Levy T, Sapir T, Sapoznik S, Fishler Y, Azoulai D, Reiner O (2004) DCX, a new mediator of the JNK pathway. EMBO J 23:823832. CrossRef Medline

Gelderblom M, Eminel S, Herdegen T, Waetzig V (2004) c-Jun N-terminal kinases (JNKs) and the cytoskeleton-functions beyond neurodegeneration. Int J Dev Neurosci 22:559-564. CrossRef Medline

Ghosh AS, Wang B, Pozniak CD, Chen M, Watts RJ, Lewcock JW (2011) DLK induces developmental neuronal degeneration via selective regulation of proapoptotic JNK activity. J Cell Biol 194:751-764. CrossRef Medline

Ghosh-Roy A, Wu Z, Goncharov A, Jin Y, Chisholm AD (2010) Calcium and cyclic AMP promote axonal regeneration in Caenorhabditis elegans and require DLK-1 kinase. J Neurosci 30:3175-3183. CrossRef Medline

Ghosh-Roy A, Goncharov A, Jin Y, Chisholm AD (2012) Kinesin-13 and tubulin posttranslational modifications regulate microtubule growth in axon regeneration. Dev Cell 23:716-728. CrossRef Medline

Goedert M, Hasegawa M, Jakes R, Lawler S, Cuenda A, Cohen P (1997) Phosphorylation of microtubule-associated protein tau by stressactivated protein kinases. FEBS Lett 409:57-62. CrossRef Medline

Goellner B, Aberle H (2012) The synaptic cytoskeleton in development and disease. Dev Neurobiol 72:111-125. CrossRef Medline

Gordon-Weeks PR (2004) Microtubules and growth cone function. J Neurobiol 58:70-83. CrossRef Medline

Grill B, Bienvenut WV, Brown HM, Ackley BD, Quadroni M, Jin Y (2007) C. elegans RPM-1 regulates axon termination and synaptogenesis through the Rab GEF GLO-4 and the Rab GTPase GLO-1. Neuron 55:587-601. CrossRef Medline

Ha EM, Lee KA, Seo YY, Kim SH, Lim JH, Oh BH, Kim J, Lee WJ (2009) Coordination of multiple dual oxidase-regulatory pathways in responses to commensal and infectious microbes in Drosophila gut. Nat Immunol 10:949-957. CrossRef Medline

Hammarlund M, Nix P, Hauth L, Jorgensen EM, Bastiani M (2009) Axon regeneration requires a conserved MAP kinase pathway. Science 323:802_ 806. CrossRef Medline

Han SJ, Choi KY, Brey PT, Lee WJ (1998) Molecular cloning and character- 
ization of a Drosophila p38 mitogen-activated protein kinase. J Biol Chem 273:369-374. CrossRef Medline

Han ZS, Ip YT (1999) Interaction and specificity of Rel-related proteins in regulating Drosophila immunity gene expression. J Biol Chem 274:2135521361. CrossRef Medline

Hirai S, Kawaguchi A, Hirasawa R, Baba M, Ohnishi T, Ohno S (2002) MAPK-upstream protein kinase (MUK) regulates the radial migration of immature neurons in telencephalon of mouse embryo. Development 129: 4483-4495. Medline

Hirai S, Cui de F, Miyata T, Ogawa M, Kiyonari H, Suda Y, Aizawa S, Banba Y, Ohno S (2006) The c-Jun N-terminal kinase activator dual leucine zipper kinase regulates axon growth and neuronal migration in the developing cerebral cortex. J Neurosci 26:11992-12002. CrossRef Medline

Hirai S, Banba Y, Satake T, Ohno S (2011) Axon formation in neocortical neurons depends on stage-specific regulation of microtubule stability by the dual leucine zipper kinase-c-Jun N-terminal kinase pathway. J Neurosci 31:6468-6480. CrossRef Medline

Horiuchi D, Barkus RV, Pilling AD, Gassman A, Saxton WM (2005) APLIP1, a kinesin binding JIP-1/JNK scaffold protein, influences the axonal transport of both vesicles and mitochondria in Drosophila. Curr Biol 15:2137-2141. CrossRef Medline

Horiuchi D, Collins CA, Bhat P, Barkus RV, Diantonio A, Saxton WM (2007) Control of a kinesin-cargo linkage mechanism by JNK pathway kinases. Curr Biol 17:1313-1317. CrossRef Medline

Huang C, Zheng X, Zhao H, Li M, Wang P, Xie Z, Wang L, Zhong Y (2012) A permissive role of mushroom body alpha/beta core neurons in longterm memory consolidation in Drosophila. Curr Biol 22:1981-1989. CrossRef Medline

Hummel T, Krukkert K, Roos J, Davis G, Klämbt C (2000) Drosophila Futsch/22C10 is a MAP1B-like protein required for dendritic and axonal development. Neuron 26:357-370. CrossRef Medline

Hur EM, Saijilafu, Zhou FQ (2012) Growing the growth cone: remodeling the cytoskeleton to promote axon regeneration. Trends Neurosci 35:164174. CrossRef Medline

Hurd DD, Saxton WM (1996) Kinesin mutations cause motor neuron disease phenotypes by disrupting fast axonal transport in Drosophila. Genetics 144:1075-1085. Medline

Inoue $\mathrm{H}$, Tateno $\mathrm{M}$, Fujimura-Kamada K, Takaesu G, Adachi-Yamada T, Ninomiya-Tsuji J, Irie K, Nishida Y, Matsumoto K (2001) A Drosophila MAPKKK, D-MEKK1, mediates stress responses through activation of p38 MAPK. EMBO J 20:5421-5430. CrossRef Medline

Itoh A, Horiuchi M, Wakayama K, Xu J, Bannerman P, Pleasure D, Itoh T (2011) ZPK/DLK, a mitogen-activated protein kinase kinase kinase, is a critical mediator of programmed cell death of motoneurons. J Neurosci 31:7223-7228. CrossRef Medline

Janke C, Kneussel M (2010) Tubulin post-translational modifications: encoding functions on the neuronal microtubule cytoskeleton. Trends Neurosci 33:362-372. CrossRef Medline

Jin Y, Garner CC (2008) Molecular mechanisms of presynaptic differentiation. Annu Rev Cell Dev Biol 24:237-262. CrossRef Medline

Kelkar N, Standen CL, Davis RJ (2005) Role of the JIP4 scaffold protein in the regulation of mitogen-activated protein kinase signaling pathways. Mol Cell Biol 25:2733-2743. CrossRef Medline

Koushika SP (2008) "JIP"ing along the axon: the complex roles of JIPs in axonal transport. Bioessays 30:10-14. CrossRef Medline

Lee CM, Onésime D, Reddy CD, Dhanasekaran N, Reddy EP (2002) JLP: a scaffolding protein that tethers JNK/p38MAPK signaling modules and transcription factors. Proc Natl Acad Sci U S A 99:14189-14194. CrossRef Medline

Lewcock JW, Genoud N, Lettieri K, Pfaff SL (2007) The ubiquitin ligase Phr1 regulates axon outgrowth through modulation of microtubule dynamics. Neuron 56:604-620. CrossRef Medline

Martín-Blanco E, Gampel A, Ring J, Virdee K, Kirov N, Tolkovsky AM, Martinez-Arias A (1998) puckered encodes a phosphatase that mediates a feedback loop regulating JNK activity during dorsal closure in Drosophila. Genes Dev 12:557-570. CrossRef Medline

Miller BR, Press C, Daniels RW, Sasaki Y, Milbrandt J, DiAntonio A (2009) A dual leucine kinase-dependent axon self-destruction program promotes Wallerian degeneration. Nat Neurosci 12:387-389. CrossRef Medline

Morfini GA, You YM, Pollema SL, Kaminska A, Liu K, Yoshioka K, Björkblom B, Coffey ET, Bagnato C, Han D, Huang CF, Banker G, Pigino G,
Brady ST (2009) Pathogenic huntingtin inhibits fast axonal transport by activating JNK3 and phosphorylating kinesin. Nat Neurosci 12:864-871. CrossRef Medline

Morfini G, Pigino G, Szebenyi G, You Y, Pollema S, Brady ST (2006) JNK mediates pathogenic effects of polyglutamine-expanded androgen receptor on fast axonal transport. Nat Neurosci 9:907-916. CrossRef Medline

Morrison DK, Davis RJ (2003) Regulation of MAP kinase signaling modules by scaffold proteins in mammals. Annu Rev Cell Dev Biol 19:91-118. CrossRef Medline

Muresan Z, Muresan V (2005) Coordinated transport of phosphorylated amyloid-beta precursor protein and c-Jun $\mathrm{NH} 2$-terminal kinaseinteracting protein-1. J Cell Biol 171:615-625. CrossRef Medline

Nakata K, Abrams B, Grill B, Goncharov A, Huang X, Chisholm AD, Jin Y (2005) Regulation of a DLK-1 and p38 MAP kinase pathway by the ubiquitin ligase RPM-1 is required for presynaptic development. Cell 120: 407-420. CrossRef Medline

Nguyen Q, Lee CM, Le A, Reddy EP (2005) JLP associates with kinesin light chain 1 through a novel leucine zipper-like domain. J Biol Chem 280: 30185-30191. CrossRef Medline

Nihalani D, Meyer D, Pajni S, Holzman LB (2001) Mixed lineage kinasedependent JNK activation is governed by interactions of scaffold protein JIP with MAPK module components. EMBO J 20:3447-3458. CrossRef Medline

Nix P, Hisamoto N, Matsumoto K, Bastiani M (2011) Axon regeneration requires coordinate activation of p38 and JNK MAPK pathways. Proc Natl Acad Sci U S A 108:10738-10743. CrossRef Medline

Osterwalder T, Yoon KS, White BH, Keshishian H (2001) A conditional tissue-specific transgene expression system using inducible GAL4. Proc Natl Acad Sci U S A 98:12596-12601. CrossRef Medline

Pack-Chung E, Kurshan PT, Dickman DK, Schwarz TL (2007) A Drosophila kinesin required for synaptic bouton formation and synaptic vesicle transport. Nat Neurosci 10:980-989. CrossRef Medline

Park JS, Kim YS, Yoo MA (2009) The role of p38b MAPK in age-related modulation of intestinal stem cell proliferation and differentiation in Drosophila. Aging 1:637-651. Medline

Reed NA, Cai D, Blasius TL, Jih GT, Meyhofer E, Gaertig J, Verhey KJ (2006) Microtubule acetylation promotes kinesin- 1 binding and transport. Curr Biol 16:2166-2172. CrossRef Medline

Reynolds CH, Utton MA, Gibb GM, Yates A, Anderton BH (1997a) Stressactivated protein kinase/c-jun N-terminal kinase phosphorylates tau protein. J Neurochem 68:1736-1744. CrossRef Medline

Reynolds CH, Nebreda AR, Gibb GM, Utton MA, Anderton BH (1997b) Reactivating kinase/p38 phosphorylates tau protein in vitro. J Neurochem 69:191-198. CrossRef Medline

Ritzenthaler S, Suzuki E, Chiba A (2000) Postsynaptic filopodia in muscle cells interact with innervating motoneuron axons. Nat Neurosci 3:10121017. CrossRef Medline

Roos J, Hummel T, Ng N, Klämbt C, Davis GW (2000) Drosophila Futsch regulates synaptic microtubule organization and is necessary for synaptic growth. Neuron 26:371-382. CrossRef Medline

Ruiz-Cañada C, Budnik V (2006) Synaptic cytoskeleton at the neuromuscular junction. Int Rev Neurobiol 75:217-236. CrossRef Medline

Sano Y, Akimaru H, Okamura T, Nagao T, Okada M, Ishii S (2005) Drosophila activating transcription factor-2 is involved in stress response via activation by p38, but not c-Jun NH(2)-terminal kinase. Mol Biol Cell 16:2934-2946. CrossRef Medline

Sathyanarayana P, Barthwal MK, Lane ME, Acevedo SF, Skoulakis EM, Bergmann A, Rana A (2003) Drosophila mixed lineage kinase/slipper, a missing biochemical link in Drosophila JNK signaling. Biochim Biophys Acta 1640:77-84. CrossRef Medline

Schaefer AM, Hadwiger GD, Nonet ML (2000) rpm-1, a conserved neuronal gene that regulates targeting and synaptogenesis in C. elegans. Neuron 26:345-356. CrossRef Medline

Schoorlemmer J, Goldfarb M (2001) Fibroblast growth factor homologous factors are intracellular signaling proteins. Curr Biol 11:793-797. CrossRef Medline

Shin JE, Cho Y, Beirowski B, Milbrandt J, Cavalli V, DiAntonio A (2012) Dual leucine zipper kinase is required for retrograde injury signaling and axonal regeneration. Neuron 74:1015-1022. CrossRef Medline

Shinzawa N, Nelson B, Aonuma H, Okado K, Fukumoto S, Miura M, Kanuka H (2009) p38 MAPK-dependent phagocytic encapsulation confers in- 
fection tolerance in Drosophila. Cell Host Microbe 6:244-252. CrossRef Medline

Stagi M, Gorlovoy P, Larionov S, Takahashi K, Neumann H (2006) Unloading kinesin transported cargoes from the tubulin track via the inflammatory c-Jun N-terminal kinase pathway. FASEB J 20:2573-2575. CrossRef Medline

Stone MC, Nguyen MM, Tao J, Allender DL, Rolls MM (2010) Global upregulation of microtubule dynamics and polarity reversal during regeneration of an axon from a dendrite. Mol Biol Cell 21:767-777. CrossRef Medline

Stronach B, Perrimon N (2002) Activation of the JNK pathway during dorsal closure in Drosophila requires the mixed lineage kinase, slipper. Genes Dev 16:377-387. CrossRef Medline

Sun F, Zhu C, Dixit R, Cavalli V (2011) Sunday Driver/JIP3 binds kinesin heavy chain directly and enhances its motility. EMBO J 30:3416-3429. CrossRef Medline

Suzanne M, Irie K, Glise B, Agnès F, Mori E, Matsumoto K, Noselli S (1999) The Drosophila p38 MAPK pathway is required during oogenesis for egg asymmetric development. Genes Dev 13:1464-1474. CrossRef Medline

Tararuk T, Ostman N, Li W, Björkblom B, Padzik A, Zdrojewska J, Hongisto V, Herdegen T, Konopka W, Courtney MJ, Coffey ET (2006) JNK1 phosphorylation of SCG10 determines microtubule dynamics and axodendritic length. J Cell Biol 173:265-277. CrossRef Medline

Taru H, Kirino Y, Suzuki T (2002) Differential roles of JIP scaffold proteins in the modulation of amyloid precursor protein metabolism. J Biol Chem 277:27567-27574. CrossRef Medline

Tedeschi A, Bradke F (2013) The DLK signalling pathway-a double-edged sword in neural development and regeneration. EMBO Rep. Advance online publication. Retrieved May 29, 2013. doi:10.1038/embor.2013.64. CrossRef Medline

Verhey KJ, Meyer D, Deehan R, Blenis J, Schnapp BJ, Rapoport TA, Margolis B (2001) Cargo of kinesin identified as JIP scaffolding proteins and associated signaling molecules. J Cell Biol 152:959-970. CrossRef Medline

Viquez NM, Li CR, Wairkar YP, DiAntonio A (2006) The B' protein phosphatase $2 \mathrm{~A}$ regulatory subunit well-rounded regulates synaptic growth and cytoskeletal stability at the Drosophila neuromuscular junction. J Neurosci 26:9293-9303. CrossRef Medline

Vrailas-Mortimer A, del Rivero T, Mukherjee S, Nag S, Gaitanidis A, Kadas D, Consoulas C, Duttaroy A, Sanyal S (2011) A muscle-specific p38 MAPK/Mef2/MnSOD pathway regulates stress, motor function, and life span in Drosophila. Dev Cell 21:783-795. CrossRef Medline

Wan HI, DiAntonio A, Fetter RD, Bergstrom K, Strauss R, Goodman CS
(2000) Highwire regulates synaptic growth in Drosophila. Neuron 26: 313-329. CrossRef Medline

Watkins TA, Wang B, Huntwork-Rodriguez S, Yang J, Jiang Z, EasthamAnderson J, Modrusan Z, Kaminker JS, Tessier-Lavigne M, Lewcock JW (2013) DLK initiates a transcriptional program that couples apoptotic and regenerative responses to axonal injury. Proc Natl Acad Sci U S A 110:4039-4044. CrossRef Medline

Weber U, Paricio N, Mlodzik M (2000) Jun mediates Frizzled-induced R3/R4 cell fate distinction and planar polarity determination in the Drosophila eye. Development 127:3619-3629. Medline

Welsbie DS, Yang Z, Ge Y, Mitchell KL, Zhou X, Martin SE, Berlinicke CA, Hackler L Jr, Fuller J, Fu J, Cao LH, Han B, Auld D, Xue T, Hirai S, Germain L, Simard-Bisson C, Blouin R, Nguyen JV, Davis CH, et al. (2013) Functional genomic screening identifies dual leucine zipper kinase as a key mediator of retinal ganglion cell death. Proc Natl Acad Sci U S A 110:4045-4050. CrossRef Medline

Whitmarsh AJ (2006) The JIP family of MAPK scaffold proteins. Biochem Soc Trans 34:828-832. CrossRef Medline

Whitmarsh AJ, Davis RJ (1998) Structural organization of MAP-kinase signaling modules by scaffold proteins in yeast and mammals. Trends Biochem Sci 23:481-485. CrossRef Medline

Whitmarsh AJ, Cavanagh J, Tournier C, Yasuda J, Davis RJ (1998) A mammalian scaffold complex that selectively mediates MAP kinase activation. Science 281:1671-1674. CrossRef Medline

Wu C, Wairkar YP, Collins CA, DiAntonio A (2005) Highwire function at the Drosophila neuromuscular junction: spatial, structural, and temporal requirements. J Neurosci 25:9557-9566. CrossRef Medline

Xiong X, Collins CA (2012) A conditioning lesion protects axons from degeneration via the Wallenda/DLK MAP kinase signaling cascade. J Neurosci 32:610-615. CrossRef Medline

Xiong X, Wang X, Ewanek R, Bhat P, Diantonio A, Collins CA (2010) Protein turnover of the Wallenda/DLK kinase regulates a retrograde response to axonal injury. J Cell Biol 191:211-223. CrossRef Medline

Yan D, Wu Z, Chisholm AD, Jin Y (2009) The DLK-1 kinase promotes mRNA stability and local translation in $C$. elegans synapses and axon regeneration. Cell 138:1005-1018. CrossRef Medline

Zhen M, Huang X, Bamber B, Jin Y (2000) Regulation of presynaptic terminal organization by C. elegans RPM-1, a putative guanine nucleotide exchanger with a RING-H2 finger domain. Neuron 26:331-343. CrossRef Medline

Zhuang ZH, Zhou Y, Yu MC, Silverman N, Ge BX (2006) Regulation of Drosophila p38 activation by specific MAP2 kinase and MAP3 kinase in response to different stimuli. Cell Signal 18:441-448. CrossRef Medline 